\title{
Pattern Analyses Reveal Separate Experience-Based Fear Memories in the Human Right Amygdala
}

\author{
[DSenne Braem, ${ }^{1,2}$ - Jan De Houwer, ${ }^{2}$ Jelle Demanet, ${ }^{1}$ Kenneth S.L. Yuen, ${ }^{3}$ Raffael Kalisch, ${ }^{3,4 *}$ and ${ }^{-M a r c e l ~ B r a s s}{ }^{1 \star}$ \\ ${ }^{1}$ Department of Experimental Psychology and ${ }^{2}$ Department of Experimental Clinical and Health Psychology, Ghent University, 9000 Ghent, Belgium, and \\ ${ }^{3}$ Neuroimaging Center Mainz, Focus Program Translational Neuroscience and ${ }^{4}$ Deutsches Resilienz-Zentrum, Johannes Gutenberg University Medical \\ Center, Mainz 55131, Germany
}

Learning fear via the experience of contingencies between a conditioned stimulus (CS) and an aversive unconditioned stimulus (US) is often assumed to be fundamentally different from learning fear via instructions. An open question is whether fear-related brain areas respond differently to experienced CS-US contingencies than to merely instructed CS-US contingencies. Here, we contrasted two experimental conditions where subjects were instructed to expect the same CS-US contingencies while only one condition was characterized by prior experience with the CS-US contingency. Using multivoxel pattern analysis of fMRI data, we found CS-related neural activation patterns in the right amygdala (but not in other fear-related regions) that dissociated between whether a CS-US contingency had been instructed and experienced versus merely instructed. A second experiment further corroborated this finding by showing a categoryindependent neural response to instructed and experienced, but not merely instructed, CS presentations in the human right amygdala. Together, these findings are in line with previous studies showing that verbal fear instructions have a strong impact on both brain and behavior. However, even in the face of fear instructions, the human right amygdala still shows a separable neural pattern response to experience-based fear contingencies.

Key words: amygdala; fear; instructions; learning

\section{Significance Statement}

In our study, we addressed a fundamental problem of the science of human fear learning and memory, namely whether fear learning via experience in humans relies on a neural pathway that can be separated from fear learning via verbal information. Using two new procedures and recent advances in the analysis of brain imaging data, we localized purely experience-based fear processing and memory in the right amygdala, thereby making a direct link between human and animal research.

\section{Introduction}

As a product of evolution, animals are equipped with the ability to learn relations that affect their survival. For example, by recognizing contingencies between certain stimuli in the environment [conditioned stimuli (CSs)] and harmful events [unconditioned stimuli (USs)], animals can learn to anticipate these events in the future, a process thought to underlie Pavlovian fear conditioning (Pav-

Received April 4, 2017; revised July 6, 2017; accepted July 10, 2017.

Author contributions: S.B., J.D.H., R.K., and M.B. designed research; S.B. and J.D. performed research;S.B., J.D., K.S.L.Y., and R.K. analyzed data; S.B., J.D.H., J.D., R.K., and M.B. wrote the paper.

This work was supported by Research Foundation Flanders (12K6316N, S.B.; G.0231.13N), the Interuniversity Attraction Poles Programme initiated by the Belgian Science Policy Office (IUAPVII/33), and Ghent University (BOF09/01M00209). We thank Dominik R. Bach, Timothy Behrens, Lauri Nummenmaa, and two anonymous reviewers for their helpful comments on earlier versions of this manuscript.

The authors declare no competing financial interests.

${ }^{*}$ R.K. and M.B. contributed equally to this work.

Correspondence should be addressed to Senne Braem, Henri-Dunantlaan 2, 9000 Gent, Belgium. E-mail: Senne.Braem@Ugent.be.

DOI:10.1523/JNEUROSCI.0908-17.2017

Copyright $\odot 2017$ the authors $\quad 0270-6474 / 17 / 378116-15 \$ 15.00 / 0$ lov, 1927; Maren, 2001). Pavlovian learning is often distinguished from other forms of fear acquisition (e.g., via instructions or observation; Olsson and Phelps, 2007) as it necessitates firsthand experiences of paired events rather than information transfer from an instructor or model. The experience-based nature and strong evolutionary conservation of Pavlovian conditioning led many theorists to think that conditioning in humans happens relatively automatically and independently from verbal processing or even awareness (Mineka and Ohman, 2002; Dolan and Vuilleumier, 2003; Olsson and Phelps, 2004; Grillon, 2009; Schultz and Helmstetter, 2010; LeDoux, 2014). Accordingly, it has been proposed that there is an evolutionary old fear module in the human brain, centered around the amygdala, that contributes to the acquisition and expression of Pavlovian fear by specifically mediating its putative nonverbal, experience-based element (Ohman and Mineka, 2001). Specifically, this theory postulates the amygdala-centered fear module to be "encapsulated," i.e., impenetrable to conscious cognitive control (Ohman and Mineka, 2001). 
If there is a brain module responsible for purely experience-based Pavlovian fear learning, it must operate relatively independently from verbally mediated or instructed fear learning. Therefore, to test whether Pavlovian fear learning can operate independently from verbally mediated fear learning, previous studies tried to isolate neural correlates of Pavlovian learning by finding evidence of conditioning in the absence of CS awareness, that is, with backwardmasked or subliminally presented CSs. These studies often pointed toward the amygdala (Morris et al., 1998; Critchley et al., 2002; Knight et al., 2009; Tabbert et al., 2011) as the neural substrate of Pavlovian fear learning, but also received substantial criticism based on methodological (potential residual CS awareness; Mitchell et al., 2009) and statistical (Vadillo et al., 2016) grounds. Even evidence for fear conditioning in nonverbal human children (Watson and Rayner, 1920) still leaves open the main question that motivated our research: once a human becomes verbal, can these verbal processes override learning pathways via experience, or do we keep separable pathways for experience-based fear conditioning instead? In other words, it remains unclear whether the human brain reserves space for the unique impact of actually experiencing CS-US pairings, in the face of explicit fear instructions.

If we want to demonstrate a truly independent, separable neural response to experience-based Pavlovian conditioning, we must contrast it to verbally mediated instruction-based learning. Therefore, rather than trying to exclude conscious or languagebased processing, as in previous studies, we here developed an experiment where conditions were optimal for verbally mediated language-based processing to override the hypothesized separate experience-based component to fear learning. To this end, we compared neural pattern responses to two CSs. While both were part of explicitly instructed contingencies, one was $\left[\mathrm{CS}^{+}\right.$Paired $\left.\left(\mathrm{CS}^{+} \mathrm{P}\right)\right]$ and the other was not $\left[\mathrm{CS}^{+}\right.$Unpaired $\left.\left(\mathrm{CS}^{+} \mathrm{U}\right)\right]$ previously paired with the US (Raes et al., 2014; Mertens et al., 2016). Hence, whereas both stimuli were expected to activate the same instruction-based fear memory during the memory-testing phase, only the previously paired $\mathrm{CS}\left(\mathrm{CS}^{+} \mathrm{P}\right)$ should additionally activate experience-based memory elements, which we here call the Pavlovian trace. This way, we studied a unique, experiencebased component of Pavlovian fear conditioning in humans. In a second experiment, we aimed to replicate and further extend this finding by testing whether a similar neural signature could be observed when comparing entirely novel (i.e., merely instructed) to old (i.e., instructed and experienced) CS presentations.

\section{Materials and Methods}

\section{General method}

In our first and main experiment, participants were first instructed that two visual stimuli $\left(\mathrm{CS}^{+} \mathrm{P}, \mathrm{CS}^{+} \mathrm{U}\right)$ could be followed by a painful electrotactile stimulus (US). A third stimulus $\left(\mathrm{CS}^{-}\right.$) was introduced as a control stimulus that would never be paired with the US. Participants were then told that, in a preparatory training phase, only one of the two $\mathrm{CS}^{+} \mathrm{s}\left(\mathrm{CS}^{+} \mathrm{P}\right)$ would be occasionally paired with an electrical stimulus, whereas the other $\mathrm{CS}^{+}\left(\mathrm{CS}^{+} \mathrm{U}\right)$ would be occasionally followed by a placeholder (drawing of a lightning bolt), under the false pretense that this limitation of the absolute number of electrical stimulations given would allow the subjects to gradually adjust to the aversive task conditions. During this training phase, we randomly presented each CS nine times; three of nine $\mathrm{CS}^{+} \mathrm{P}$ presentations were followed by a US, making subjects experience the $\mathrm{CS}^{+} \mathrm{P}-\mathrm{US}$ contingency, while three of nine $\mathrm{CS}^{+} \mathrm{U}$ presentations were followed by the placeholder (Fig. 1). Before the subsequent test phase, participants were reinstructed that, from then on, both $\mathrm{CS}^{+} \mathrm{s}$ could be followed by a US. In fact, no more USs were delivered, keeping this critical phase of the experiment free of any Pavlovian fear learning. Because instructions in the test phase were identical for both $\mathrm{CS}^{+} \mathrm{s}$, neural activity patterns associated exclusively with the $\mathrm{CS}^{+} \mathrm{P}$ during the test phase would reflect a Pavlovian trace of actual CS-US pairings. This procedure has been tested before by Raes and colleagues (2014) and Mertens and colleagues (2016) but without simultaneous MRI recordings. Therefore, the behavioral data discussed here are compared with data from those studies.

A second experiment was performed to examine whether our main finding could also be observed in a different, but conceptually similar procedure. As an additional motivation, this second experiment also allowed us to examine whether a higher visual category-independent neural response to instructed and experienced CS presentations could be observed, compared with merely instructed CS presentations. This experiment was different in design from Experiment 1, but nonetheless allowed for a similar comparison between instructed and experienced versus merely instructed fear. Specifically, we used a broad range of different CSs (house or face pictures), and participants were instructed on the relevant CS-US contingencies before each CS presentation (see Fig. $8 A$ ). That is, each trial of this experiment started with the presentation of an instruction screen that defined the $\mathrm{CS}^{+}$and the $\mathrm{CS}^{-}$, followed by the presentation of the $\mathrm{CS}^{+}$or $\mathrm{CS}^{-}$. Each $\mathrm{CS}^{+}$was in its turn followed by a US presentation. This way, participants saw many different CS instructions. Importantly, however, whereas some contingency instructions (and the experience thereof) recurred multiple times throughout the experiment (i.e., old CS stimuli), others were always new (i.e., new CS stimuli). Hence, some contingencies had been "instructed and experienced," whereas, for new CSs, this was not the case. The new CSs could therefore be considered "merely instructed."

In contrast to Experiment 1, Experiment 2 also allowed for a comparison within CS conditions but across visual stimuli or visual categories. Specifically, the different CS instructions could be further subdivided into those that used pictures of faces as CSs, and those that used pictures of houses as CSs. This way, we could compute the similarity in neural activation patterns at the time of CS presentation between faces versus houses separately (see Fig. 8B) for each of the four different CS presentation conditions: $\mathrm{CS}^{+}$old, $\mathrm{CS}^{-}$old, $\mathrm{CS}^{+}$new, and $\mathrm{CS}^{-}$new. By computing similarities between responses to faces and houses, this study allowed us to investigate to which extent fear-related regions showed a neural response independent from CS object category, and thus specific to whether a CS carried a representation of threat $\left(\mathrm{CS}^{+} \mathrm{vs} \mathrm{CS}^{-}\right)$or whether it was old or novel (CSold vs CSnew). Following up on the findings of the first experiment, we zoomed in on the pattern similarities in the left and right amygdala. We were especially interested in whether the right amygdala would show a higher similarity between face-evoked and house-evoked patterns when a $\mathrm{CS}^{+}$was old, which would indicate a representation of threat sensitive to whether a contingency had been experienced before.

\section{Participants}

Twenty participants took part in Experiment 1 (12 women and eight men; mean age, 24 years; SD, 2.5 years; range, $19-28$ years), and another 20 in Experiment 2. One participant from Experiment 2 was excluded from analyses due to self-reported nausea and inattention to the task, so the final sample of Experiment 2 contained 19 participants (10 women and nine men; mean age, 24 years; SD, 3.7 years; range, $18-34$ years). All participants had normal or corrected-to-normal vision, and were righthanded as assessed by the Edinburgh Handedness Inventory. They gave their informed written consent and reported no current or past neurological, psychiatric, or major medical disorder. Every participant was paid $€ 35$ for participating. The work has been completed with the approval of the Ghent University Hospital Ethical Committee.

\section{Stimuli and procedure: Experiment 1}

Stimuli. The conditioned stimuli consisted of three dissociable blue fractal figures (snowflakes) presented on a white background. Counterbalanced across participants, one of the fractals served as a CS that would never be followed by an electrotactile pain stimulus $\left(\mathrm{CS}^{-}\right)$, another served as a CS that could occasionally be followed by a pain stimulus $\left(\mathrm{CS}^{+} \mathrm{P}\right)$, and a third as a CS that subjects were told could be followed by 


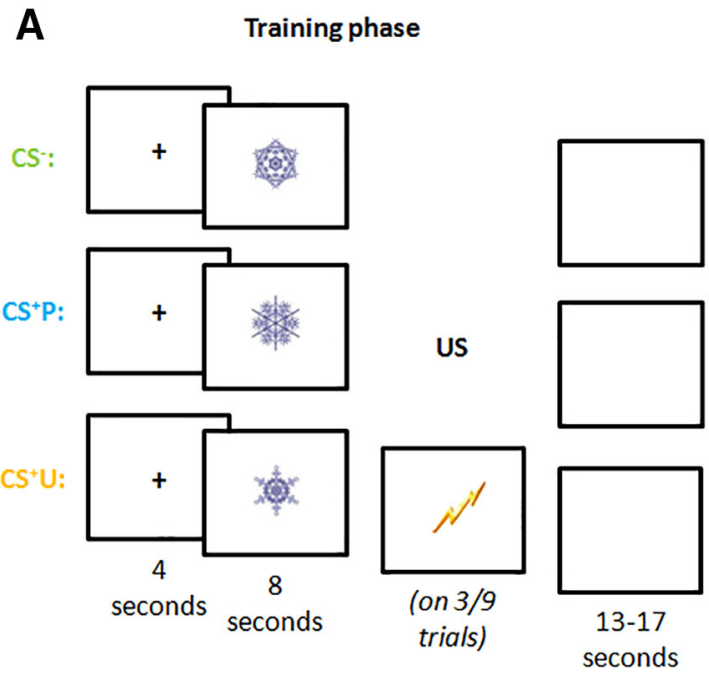

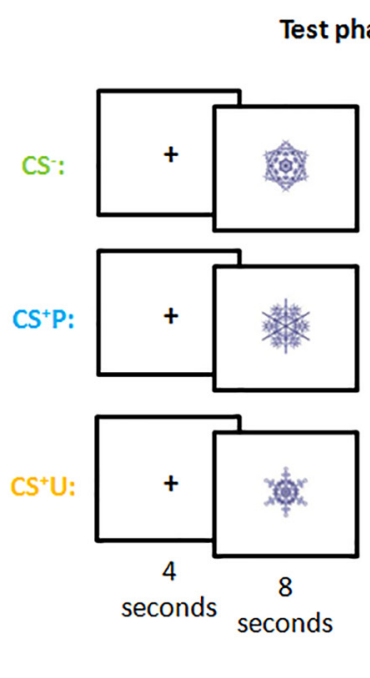

Instructions
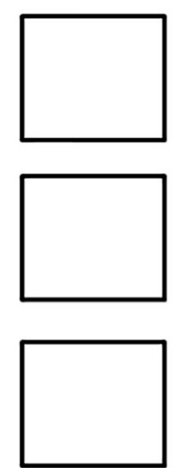

13-17 seconds
Fear Rating:

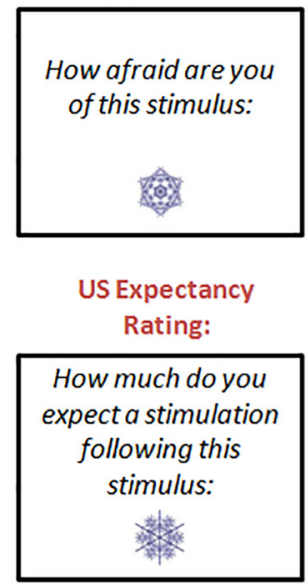

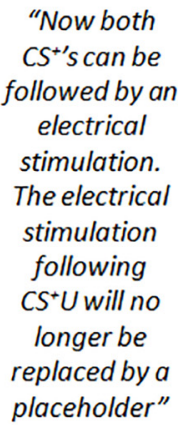

Test phase

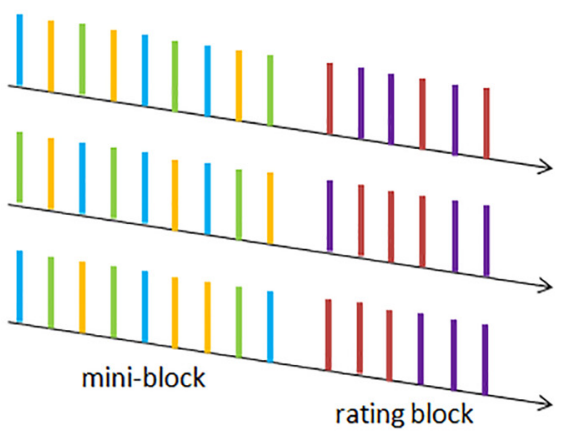

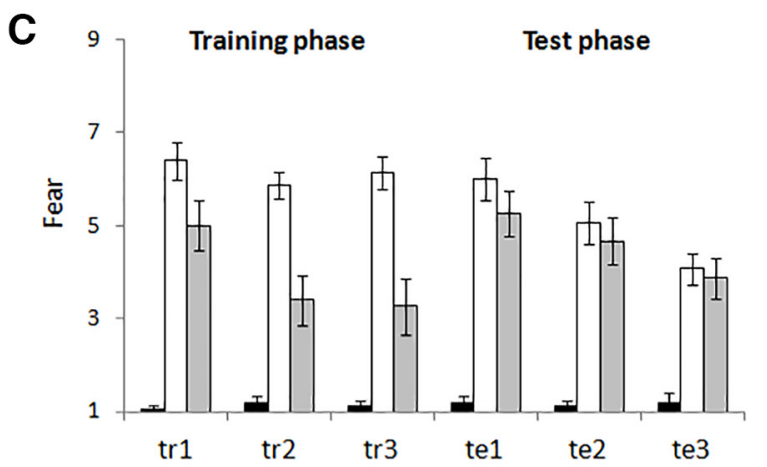

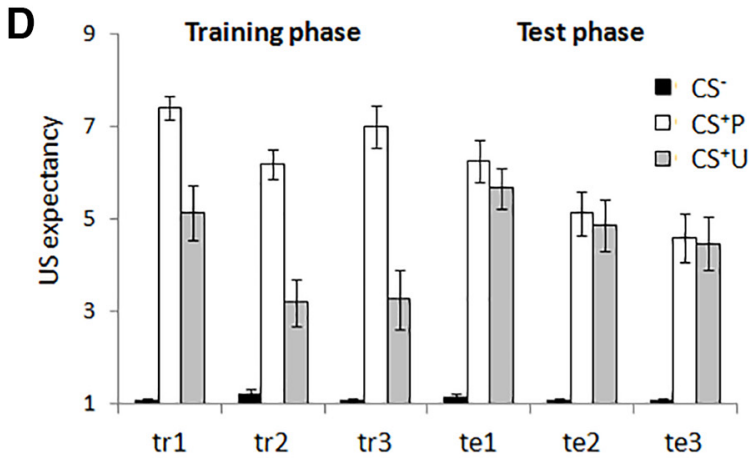

Figure 1. Procedure Experiment 1 and behavioral results. $\boldsymbol{A}$, Experiment trials and rating screens. Each trial started with the presentation of a fixation cross, followed by the presentation of a $C S$. In the training phase, the CS ${ }^{+}$P was occasionally followed by a US (electrical stimulation) and the $\mathrm{SS}^{+} \mathrm{U}$ by a US placeholder (picture of a lightning bolt). The CS ${ }^{-}$was never followed by either a US or placeholder. In the test phase, none of the CSs was followed by a US or placeholder. Rating screens assessed participant's fear experience and US expectancy associated with each of the CSs. $\boldsymbol{B}$, Experimental procedure and instructions. Before training, subjects were instructed that only the $\mathrm{CS}^{+} \mathrm{P}$ could be followed by the US, while the CS ${ }^{+} \mathrm{U}$ could only be followed by the placeholder. Before testing, subjects were told to expect USs after both $C S^{+}$s. Both phases consisted of three miniblocks (where every $C S$ was randomly presented three times), each followed by a rating block. Three of nine CS ${ }^{+}$presentations were followed by either the US or the US placeholder. C, Mean fear ratings. D, Mean US expectancy ratings. The error bars are \pm 1 SEM. tr, Training; te, test.

a pain stimulus, but was actually only occasionally followed by a placeholder $\left(\mathrm{CS}^{+} \mathrm{U}\right)$. The electrotactile pain stimulus that served as the aversive stimulus (US) consisted of a train of 12 square-wave pulses of $2 \mathrm{~ms}$ duration each (interval, $18 \mathrm{~ms}$ ). The US was delivered through a surface electrode with a platinum pin (Specialty Developments) onto the right leg over the retromalleolar course of the sural nerve using a DS5 electrical stimulator (Digitimer). The intensity was determined through a standard work-up procedure before the experiment (see below). The placeholder consisted of a centrally presented yellow drawing of a lightning bolt.

Ratings. Self-reported CS fear and US expectancy were assessed for all CSs in separate rating blocks interspersed between conditioning trials. These ratings were performed on screen. On a typical rating trial, the CS was presented centrally, while the question on fear or US expectancy was situated on top of the CS and a rating scale was presented below. Before each rating phase, participants were instructed to respond to the questions that would appear at the top of the screen by selecting the response possibility that felt most appropriate to them. Furthermore, it was stressed that these questions pertained to their most recent encounter with the CSs during the foregoing (conditioning) phase. In addition, participants were given the following instructions: "Whenever you are asked about your expectancy of an electrical stimulus, we refer to the actual stimulation, not to the picture of the lightning bolt." The questions that appeared were as follows: "How much fear did you experience when looking at this figure?" (self-reported CS fear) and "To what extent did 
you expect an electrical stimulation while looking at this figure?" (US expectancy). Participants responded verbally on a nine-point Likert scale. Numbers $1,3,5,7$, and 9 of this scale carried a response label presented right above the number ( 1 , none at all/certainly not; 3 , very little/rather not; 5 , uncertain; 7 , somewhat/to some extent; 9 , very much/ most certainly).

Procedure. The experimenter attached the electrodes to the participant, who was positioned on the scanner table, just before the table was inserted into the scanner. Next, the tolerance level of the pain stimulus was determined for each participant individually by means of an adapted interleaved staircase procedure. This procedure consisted of 20 trials where USs were presented and participants rated the subjectively experienced pain intensity on a scale from zero (not painful at all) to 10 (extremely painful). To increase reliability of the threshold procedure, the 20 trials were divided into two separate sequences of 10 trials differing in current amplitude on their first trial, which was randomly drawn from either $0.5-1.0 \mathrm{~mA}$ or $1.0-1.5 \mathrm{~mA}$, respectively. After the first trial of each sequence, the current amplitude of the following trial depended on the participant's rating in the previous trial of the respective sequence. If the rating was $<5$, current amplitude would increase by $0.1 \mathrm{~mA}$ in the following trial of that sequence, whereas it would decrease by $0.1 \mathrm{~mA}$ in case of a rating $>5$, or stay the same if the rating equaled five. Thus, ratings from both sequences would approach five on the rating scale for each participant. The two sequences were presented intermixed and the final electrical current amplitude was then calculated as the mean of the final values from both sequences. Participants were instructed to rate an intensity five when it was experienced as unpleasant, but not intolerable, and were informed that the pain stimuli used throughout the experiment would not surpass this value.

After this preparation phase, the participants were instructed to wait for $5 \mathrm{~min}$, during which an anatomical scan would be administered. Upon completion of the anatomical scan, the participants were presented with the instructions. Participants were informed that three fractal figures (Fig. 1A) would appear successively for $8 \mathrm{~s}$ each. Following the presentation of all three fractals on a white background, the participants were instructed that two of the fractals would sometimes be followed by an electrical stimulation, whereas the third fractal would never (in capital letters) be followed by an electrical stimulation. Subsequently, participants were informed that these fractal-pain contingencies would be clearly displayed and were encouraged to closely attend to these contingencies. After this instruction, a slide containing both $\mathrm{CS}^{+}$fractals and the text "+ electrical stimulation!" was presented over $8 \mathrm{~s}$. This was followed by another $8 \mathrm{~s}$ presentation of a slide containing the $\mathrm{CS}^{-}$ fractal and the following text: "This figure will never be followed by a stimulation."

Following these general instructions, the participants were informed that they would first be allowed to familiarize themselves with the stimuli and the procedure in an initial training phase. The training phase was said to be very similar to the test phase that would follow, except that some of the electrical stimulations would be replaced by a picture of a lightning bolt (i.e., the placeholder stimulus; Fig. 1A). Participants were told that this was to prevent them from getting too many pain stimuli before the real experiment actually started. They were asked to keep in mind that whenever a lightning bolt was presented in the actual test phase, a real electrical stimulation would occur. This was followed by a slide presenting the $\mathrm{CS}^{+} \mathrm{P}$ (with electrical stimulation) and $\mathrm{CS}^{+} \mathrm{U}$ (with lightning bolt) contingencies over $8 \mathrm{~s}$. The final page of instructions informed participants that they would be asked to perform fear and US expectancy ratings at regular intervals during the upcoming phase. They were told that no stimuli would be administered during the ratings and asked to remember the most recent encounter with the fractals while answering the questions.

The actual training phase consisted of 27 conditioning trials (nine for each CS) interspersed with blocked ratings. Each conditioning trial started with a $4 \mathrm{~s}$ presentation of a fixation cross followed by a CS presentation for $8 \mathrm{~s}$, with an intertrial interval of 13,15 , or $17 \mathrm{~s}$ (Fig. $1 A$ ). On reinforced trials, the US or placeholder was presented at $\mathrm{CS}^{+}$offset. The US was presented for $300 \mathrm{~ms}$. The placeholder remained on screen for $500 \mathrm{~ms}$. The CSs were presented in "triplets" of three CS presentations so that each CS type was presented once before the next triplet started. Trial order was randomized within triplets. Blocked ratings of fear and US expectancy were presented after 9,18 , and 27 conditioning trials $(3,6$, and 9 triplets) respectively. As such, three miniblocks were created within the training phase, each containing three trials of $\mathrm{CS}^{+} \mathrm{P}, \mathrm{CS}^{+} \mathrm{U}$, and $\mathrm{CS}^{-}$ presentations. Three of nine $\mathrm{CS}^{+} \mathrm{P}$ and $\mathrm{CS}^{+} \mathrm{U}$ presentations were reinforced during the training phase. For half the participants, the first, third, and penultimate presentation of the $\mathrm{CS}^{+} \mathrm{P}$ was followed by the US and the first, second, and last presentation of the $\mathrm{CS}^{+} \mathrm{U}$ was followed by the placeholder. The other half of the participants had counterbalanced reinforcement schedules (e.g., the first, second, and last presentation of the $\mathrm{CS}^{+} \mathrm{P}$ would be followed by the US).

Each block of ratings contained six ratings (two for each CS). The order of rating trials within each rating block was fully randomized. However, due to technical difficulties, the CS presentation and question type were independently randomized within each rating block for the first five participants, resulting in repeated measurements or empty cells for some of the questions. For this reason, the rating analyses are reported for the last 15 subjects only. Brain-behavior correlation analyses, however, which focus on averaged CS ratings for an entire phase (across the three rating blocks), were possible to perform on the entire set of participants. Before the start of each rating block, it was stressed that by electrical stimulation (expectancy), we referred solely to real electrical stimulations (i.e., not placeholders).

After the training phase, participants again received on-screen instructions. They were informed that now the test phase would start, meaning that all electrical stimulations would be presented for real and no placeholders would be used. Participants were instructed that the test phase would evolve similarly to the training phase in all other respects. The course of the test phase was very similar to that of the test phase, with 27 trials and three rating blocks in between. However, no USs or placeholders were presented during this phase.

\section{Stimuli and procedure: Experiment 2}

Stimuli. The stimuli for Experiment 2 were gray-scaled images selected from a database of 252 images of faces and 252 images of houses as previously used by Muhle-Karbe and colleagues (2017). For each subject separately, 128 pictures ( 64 from each category) were randomly selected and assigned to 64 pairs of pictures with the only restriction that both pictures should be from the same category. When the category was faces, we further assured participants that both pictures were from the same gender (and an equal number of pairs were formed per gender), to avoid the possibility that participants would dissociate the pictures based on gender. Per pair, one picture served as a CS that would never be followed by an electrical stimulation $\left(\mathrm{CS}^{-}\right)$, while another served as a CS that would always be followed by an electrical stimulation $\left(\mathrm{CS}^{+}\right)$. While eight pairs of $\mathrm{CS}^{-}$and $\mathrm{CS}^{+}$pictures would reoccur throughout the experiment (four pairs of houses, two pairs of male faces, and two pairs of female faces), the 56 remaining pairs only appeared once, hereafter referred to as "old" and "new" stimuli, respectively. The electrotactile stimulus (US) consisted of the same sequence of pulses, and was applied to the same location, as in Experiment 1. Unlike Experiment 1, however, the intensity could either be low or high (see below). The instructions would indicate the intensity of the electrotactile stimulus that potentially could follow by showing a gray intensity meter that either pointed to the left or the right, indicating a low or high intensity, respectively (see Fig. 8A).

Procedure. Before entering the scanner, the participants were shown an example trial of the experiment (without electrotactile stimulation) and were instructed about the general procedure of the experiment. Specifically, participants were informed that they would encounter several instruction screens where two pictures were presented, one above the other, on the left side of the screen and an intensity meter on the right side of the screen, next to one of the two pictures (see Fig. 8A). It was further explained to the participants that after these instruction screens, one of the two pictures would be presented (i.e., CS presentation) in the center of the screen. If this picture was presented next to the intensity meter during the instructions, they would receive an electrotactile stimulation shortly afterward. The intensity of this stimulation was dependent on which direction the intensity meter pointed to. To ensure that partici- 
pants paid attention to the task, one of eight CS presentations (or one of four in the practice block) were replaced by a catch question where participants were shown either one of the two CSs, or a third picture that they had never seen before (of the same category). On these trials, their task was to indicate whether this picture was instructed to be followed by a stimulation, not followed by a stimulation, or never presented before (all participants performed above chance level on these catch questions; mean, 87.1\%; SD, 10.6\%; minimum, 67\%; maximum, 100\%). Last, on some trials, participants would also see a centrally presented intensity meter, which would indicate that an electrotactile stimulus could follow with a $50 \%$ probability. These trials are hereafter referred to as control trials. Briefly, this last condition was designed to control for general US expectancy effects during instruction presentation, but is not important for the current focus of analysis.

Next, participants were placed on the scanner table and, after attaching the electrode, the tolerance level was determined for each subject separately. The two intensities were determined through a work-up procedure where gradually increasing current amplitudes were presented to the participant. Participants were asked to determine which amplitude was the first noticeable, and when we should stop increasing the amplitude, upon which the work-up procedure automatically ended. The first noticeable current level was used as the low intensity, the last tolerable as the high intensity. We assured subjects that only those two intensities could be used in the remainder of the experiment.

After the anatomical scan, we presented the instructions to the participant once more. They were further informed that they would receive a practice block half the length of the following three experimental blocks. This practice block was to ensure that participants were familiarized with all the "old" pairs, and was not included in the analyses.

During each block, the participant was presented with an equal number of all three possible trial types: old instructed trials, new instructed trials, and control trials. The general structure of each of those trial types was that they started with $2500 \mathrm{~ms}$ instruction presentation, followed by a 2000-4200 ms instruction-CS interval, a $1000 \mathrm{~ms}$ CS presentation, 2000-4200 ms CS-US interval, a $300 \mathrm{~ms}$ US presentation (if the CS was a $\mathrm{CS}^{+}$), and, finally, a 2500-4700 ms intertrial interval. For instructed trials, instruction presentation consisted of a presentation of the $\mathrm{CS}^{-}$ and $\mathrm{CS}^{+}$picture, one above the other, on the left side of the screen (location of CS type was randomly determined per trial), and an intensity meter next to the $\mathrm{CS}^{+}$picture. On control trials, instruction presentation consisted of a centrally presented intensity meter. CS presentation on instructed trials consisted of one of the two CSs $\left(\mathrm{CS}^{-}\right.$or $\left.\mathrm{CS}^{+}\right)$centrally presented on screen. During control trials, this was replaced by the presentation of a central fixation cross.

Each test block consisted of 16 new instructed trials, 16 old instructed trials (each specific pair was presented twice per block), and 16 control trials. All trial types were further subdivided in eight high-intensity and eight low-intensity trials. The instructed trial types also showed an equal number of faces and houses (and an equal number of male and female pictures among the faces). The different trials were presented in a random order.

\section{fMRI data acquisition}

In both experiments, participants were positioned head first and supine and instructed not to move their heads to avoid motion artifacts. Images were collected using a 3T Magnetom Trio MRI scanner system (Siemens Medical Systems) with a standard 32-channel radio-frequency head coil. First, a 3D high-resolution anatomical image of the whole brain was acquired for coregistration with the functional images using a T1weighted 3D MPRAGE sequence $(\mathrm{TR}=2530 \mathrm{~ms}$; $\mathrm{TE}=2.58 \mathrm{~ms}$; $\mathrm{TI}=$ $1100 \mathrm{~ms}$; acquisition matrix, $256 \times 256 \times 176$; sagittal FOV, $220 \mathrm{~mm}$; flip angle, $7^{\circ}$; voxel size, $0.9 \times 0.86 \times 0.86 \mathrm{~mm}$ ). Next, whole-brain functional images were collected using a $\mathrm{T} 2^{\star}$-weighted EPI sequence, sensitive to BOLD contrast $(\mathrm{TR}=2000 \mathrm{~ms}, \mathrm{TE}=28 \mathrm{~ms}$, image matrix $=64 \times$ 64 , FOV $=224 \mathrm{~mm}$, flip angle $=80^{\circ}$, slice thickness $=3 \mathrm{~mm}$, distance factor $=17 \%$, voxels resized to $3.0 \times 3.0 \times 3.0 \mathrm{~mm}, 34$ axial slices). The number of images per run varied depending on response speed during the rating blocks (Experiment 1) or catch questions (Experiment 2).

\section{Experimental design and statistical analysis}

Behavioral data analyses for Experiment 1. We performed two ANOVAs with the three within-subjects factors phase (training vs test), CS type $\left(\mathrm{CS}^{+} \mathrm{P}, \mathrm{CS}^{+} \mathrm{U}\right.$, and $\left.\mathrm{CS}^{-}\right)$, and block (first, second, or third rating block) for each rating scale separately. Further ANOVAs focused on specific CS contrasts (e.g., $\mathrm{CS}^{+} \mathrm{P}$ vs $\mathrm{CS}^{+} \mathrm{U}$ ) to allow for a more detailed picture of the significant interactions observed in the main ANOVA. Due to incomplete data collection for the first five subjects, we performed all behavioral ANOVAs on 15 subjects. Analyses excluding the factor block allowed us to study 19 subjects and all 20 subjects for the fear and US expectancy data (one subject did not have any fear ratings for the $\mathrm{CS}^{-}$), respectively. Including these subjects did not change the significance of our findings. However, the factor block was, naturally, excluded from these analyses. Therefore, we only report the overall ANOVA. We did, however, use these general ratings (across blocks) to investigate brainbehavior correlations.

Introduction to representational similarity analyses. A traditional mass univariate voxelwise comparison of CS-related activations in canonical fMRI analyses can inform about gross differences in the recruitment of brain regions at the macroscopic scale but is blind to differences in the recruitment of separable neural ensembles within a brain region. More recently, multivariate multivoxel pattern analysis techniques have made possible investigations of intraregional spatial patterns of neuronal activation (Haxby et al., 2001; Norman et al., 2006; Kriegeskorte et al., 2008), including in fear conditioning (Li et al., 2008; Bach et al., 2011; Visser et al., 2011, 2013; Hauner et al., 2013; Dunsmoor et al., 2014), with high sensitivity, often going beyond conclusions that can be derived from univariate analyses (notably, the latter did not show any significant differences in $\mathrm{CS}^{+} \mathrm{P}$ vs $\mathrm{CS}^{+} \mathrm{U}$ activity during the test phase, neither in a whole-brain corrected contrast, nor when restricting the analysis to any of the regions defined below). We therefore investigated similarities and dissimilarities in neural processing of different CSs or of the same CS at different time points of the experiment by extracting and comparing multivoxel activation pattern data from previously selected regions of interest (ROIs) event-locked to the presentation of the different CSs (Kriegeskorte et al., 2008).

fMRI data analyses. Data processing and analyses were performed using the SPM8 Matlab-package software (http://www.fil.ion.ucl.ac.uk/ $\mathrm{spm} / \mathrm{software} / \mathrm{spm} 8 /$ ). The first four volumes of each run in which no stimulation occurred were discarded before estimating statistical models. Anatomical images were spatially normalized to the SPM T1-template image and resliced to a voxel size of $1 \times 1 \times 1 \mathrm{~mm}$. Functional data were slice-time corrected and spatially realigned to the first volume of the task. Next, EPIs were spatially normalized based on the T1-derived normalization parameters and a temporal high-pass filter of $128 \mathrm{~s}$ was applied to remove low-frequency drifts. No spatial smoothing was used.

In Experiment 1, BOLD responses were modeled with boxcar functions at CS onset till CS offset $(8 \mathrm{~s})$ or with $\delta$ functions for all other regressors, which were then convolved with a standard hemodynamic response function. Event-related regressors were created corresponding to the onset of the CS and defined by CS type $\left(\mathrm{CS}^{-}, \mathrm{CS}^{+} \mathrm{P}\right.$, or $\left.\mathrm{CS}^{+} \mathrm{U}\right)$, corresponding to the onset of US and defined by US type (electrotactile stimulation or placeholder), or corresponding to the onset of a ratings question. Specifically, the model included three (or more; see below) regressors denoting the CS type, one for the ratings, two for the US type (in the training phase only), and six movement parameters derived from the realignment procedure, for the two runs separately (which corresponded with the training and test phase, respectively). The statistical parameter estimates were computed separately for each voxel for all columns in the design matrix. Three different first-level models were fitted. The CS-type regressors per phase were either further split up in a single regressor for each trial separately (i.e., the trial-based model), in a regressor for each miniblock separately (i.e., the miniblock model), or in a regressor per phase (i.e., the phase model). We analyzed the resulting data by computing pairwise Pearson correlations between all CS eventrelated spatial patterns of activation. For a visual depiction of the resulting similarity matrices from these three types of models in the anterior cingulate cortex (ACC), see Figure 2. The strength of these correlations was used as a metric of similarity. The correlations were Fisher-transformed 


\section{A Similarity Matrix per Trial}

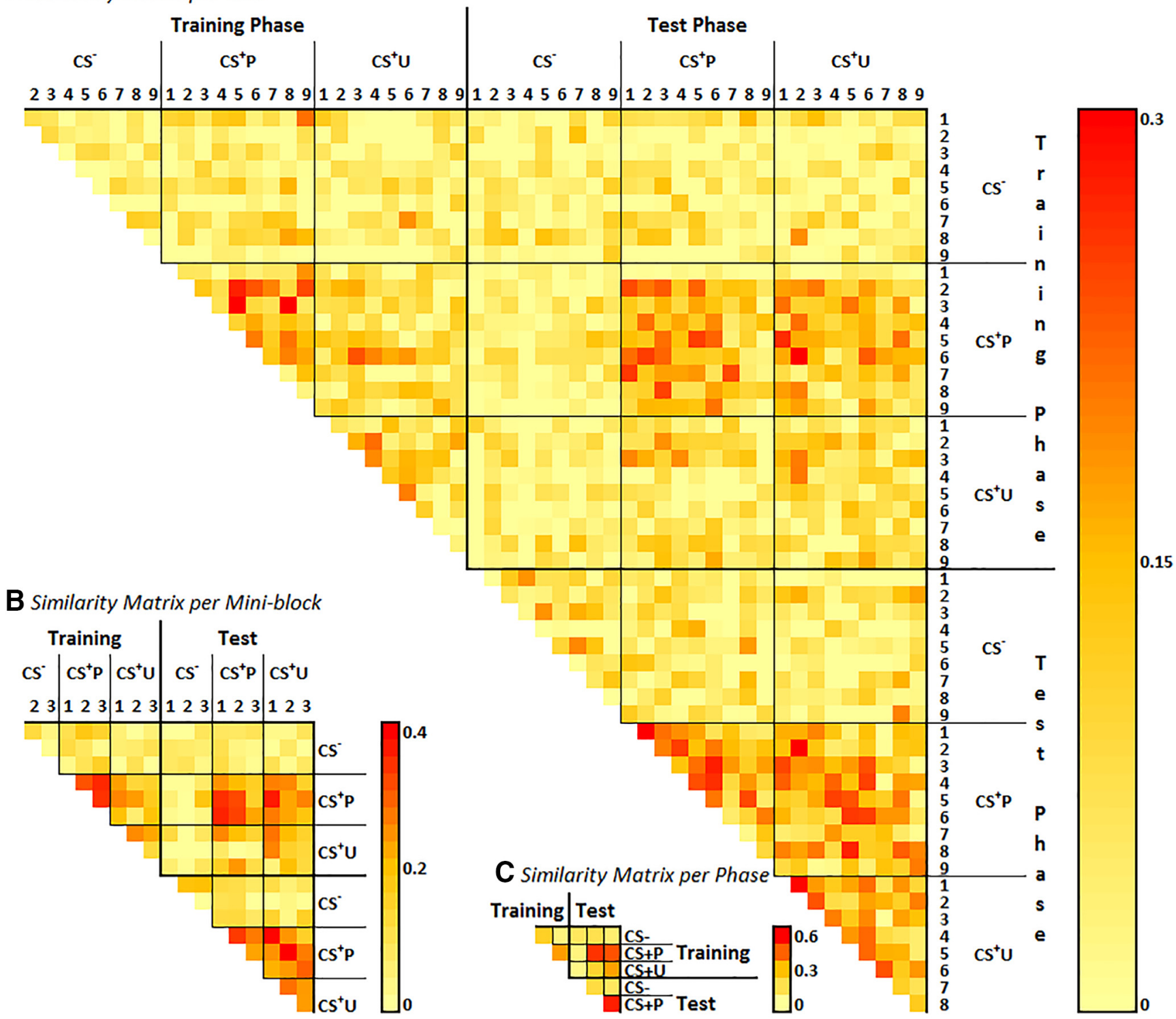

Figure 2. An example of the different types of similarity matrices in the anterior cingulate cortex (Experiment 1). $\boldsymbol{A}-\boldsymbol{C}$, The similarity matrices represent color-coded average Pearson correlation coefficients across subjects for every possible correlation between all different CS-presentation regressors in the trial-based model $(\boldsymbol{A})$, miniblock model $(\boldsymbol{B})$, or phase model $(\boldsymbol{C})$. The vertical bars adjacent to each matrix indicate its color coding depending on the correlation coefficient.

for statistical analyses. Different types of correlations were selected for the analyses of interest and analyzed in ANOVAs using Statistical Package for the Social Sciences (version 22, SPSS). Each analysis started with an overall ANOVA, including the factor region, whose six levels corresponded to the six ROIs identified below. Only when effects interacted with the factor region were the effects further studied for each region separately. All reported $p$ values are two-sided and a Greenhouse-Geisser correction was applied whenever the assumption of sphericity was violated, but uncorrected degrees of freedom are reported for ease of reading.

Task events in Experiment 2 were similarly modeled as in Experiment 1 , only now we also added separate regressors for instruction presentations (also modeled with boxcar functions from instruction onset till instruction offset, $2500 \mathrm{~ms}$ ). In total, 31 event-related regressors were created. Eight regressors corresponded to the onset of instruction presentation and were defined by instruction type (coding for either old vs new instructions, house vs face stimuli, and low vs high US intensity), 16 corresponded to the onset of CS presentation defined by CS-type (similarly determined by the same conditions as instruction type and further coding for being a $\mathrm{CS}^{-}$or $\mathrm{CS}^{+}$presentation), four corresponded to the onset of control instructions and the subsequent fixation cross presentation (further determined by low or high intensity), two corresponded to the onset of US presentations and were defined by being either of low or high intensity, and, finally, one corresponded to the onset of catch questions. Although instruction presentations, US presentations, and catch trials were modeled separately, they were not included in our contrasts and were considered regressors of noninterest. For the analysis of this dataset, we only focused on high-intensity trials, where the $\mathrm{CS}^{+}$was instructed and expected to be followed by a high-intensity electrical stimulation. Specifically, we focused on voxel patterns evoked by CS presentation in any of the six ROIs defined below. We again analyzed the resulting data by computing Fisher-transformed pairwise Pearson correlations. We were especially interested in the correlations between house and face presentations of the same trial type (see Fig. $8 B$ ). This way, we created four possible correlations of interest: the correlations between multivoxel patterns of activity to face presentation versus house presentation for $\mathrm{CS}^{-}$old trials, $\mathrm{CS}^{+}$old trials, $\mathrm{CS}^{-}$new trials, and $\mathrm{CS}^{+}$new trials, separately. These values were interpreted as the degree to which a 
certain region showed a response independent of visual category. Next, these values were analyzed using two-by-two ANCOVAs with the factors fear relevance $\left(\mathrm{CS}^{+}{ }^{-}\right.$vs $\mathrm{CS}^{-}$) and novelty (old vs new), and, to control for differences in preferred US intensity, the standardized covariate US intensity (baseline-corrected by dividing the high-intensity value by the low-intensity value), for each ROI separately.

$R O I$ analyses. We extracted $\beta$ estimates from the separate voxels of anatomically defined ROIs, known to be relevant in fear conditioning (the same fear-related regions as were used by Visser et al., 2013). Specifically, in addition to the amygdala, we focused on the ACC, the superior frontal gyrus, the insula, and the ventromedial prefrontal cortex, areas previously implicated in fear conditioning (Mechias et al., 2010; Visser et al., 2013; Fullana et al., 2015). We extracted the mean voxel activation from those regions, as obtained from the Harvard-Oxford cortical and subcortical structural atlases (Harvard Center for Morphometric Analysis), thresholded at 25\%, and included a factor "region" in each of our analyses to identify potential between-region differences.

\section{Results}

\section{Experiment 1: rating data}

In the rating data, by analyzing the mean fear and US expectancy ratings per phase and block, we tested whether we could replicate the behavioral results reported by Raes and colleagues (2014) and by Mertens and colleagues (2016). There was a clear main effect of CS type for both ratings (both $p$ 's $<0.001$ ), which interacted with phase (both $p$ 's $<0.001$; Fig. $1 B, C$ ). Marginal significant three-way interactions between phase, CS type, and block for both the fear $\left(F_{(4,11)}=3.4, p=0.050\right)$ and US expectancy ratings $\left(F_{(4,11)}=2.7, p=0.088\right)$ hinted at a differential evolution of CS ratings over time, depending on the phase.

Next, by running separate block $\times$ CS-type ANOVAs, we investigated these interactions for each CS-type comparison and phase separately. In the training phase, both the $\mathrm{CS}^{+} \mathrm{P}$ and $\mathrm{CS}^{+} \mathrm{U}$ elicited a higher US expectancy and fear rating, relative to the $\mathrm{CS}^{-}$(all $p$ 's $\left.<0.001\right)$. Moreover, the $\mathrm{CS}^{+} \mathrm{P}$ elicited higher ratings on both scales relative to the $\mathrm{CS}^{+} \mathrm{U}$ (both $p^{\prime} \mathrm{s}<0.005$ ). In the testing phase, again both the $\mathrm{CS}^{+} \mathrm{P}$ and $\mathrm{CS}^{+} \mathrm{U}$ elicited higher ratings relative to the $\mathrm{CS}^{-}$(all $p$ 's $<0.001$ ). The $\mathrm{CS}^{+} \mathrm{P}$, however, was no longer significantly different from the $\mathrm{CS}^{+} \mathrm{U}$ on both the fear $\left(F_{(1,14)}=1.3, p=0.272\right)$ and the US expectancy $\left(F_{(1,14)}=\right.$ $1.2, p=0.277)$ scale, suggesting similar fear responses.

For all $\mathrm{CS}^{+}$to $\mathrm{CS}^{-}$comparisons, on both phases, there was a significant interaction between CS type and block (all p's < 0.001 ), suggesting that $\mathrm{CS}^{+}$ratings did, while $\mathrm{CS}^{-}$ratings did not, decay over time, regardless of the phase (Fig. $1 B, C$ ). Interestingly, however, similar interactions between CS type and block between $\mathrm{CS}^{+} \mathrm{P}$ and $\mathrm{CS}^{+} \mathrm{U}$ were absent in the training phase $\left(F\right.$ s $\left.<1.7, p^{\prime} s>0.21\right)$ but present in the testing phase, with a significant interaction for the fear ratings $\left(F_{(2,13)}=12.0, p=\right.$ $0.001)$ and a marginally significant interaction in the US expectancy data $\left(F_{(2,13)}=1.2, p=0.052\right)$. These interactions demonstrated that while there was no overall difference between both $\mathrm{CS}^{+}$ratings in the test phase, there were some initial differences in the first miniblocks of the test phase (Fig. $1 B, C$ ). Specifically, the fear rating for $\mathrm{CS}^{+} \mathrm{P}$ relative to $\mathrm{CS}^{+} \mathrm{U}$ was significantly higher in the first block $\left(t_{(14)}=2.22, p=0.044\right)$, marginally significant in the second block $\left(t_{(14)}=1.87, p=0.082\right)$, and absent in the third block $\left(t_{(14)}=0.76, p=0.458\right)$. The US expectancy rating for $\mathrm{CS}^{+} \mathrm{P}$ relative to $\mathrm{CS}^{+} \mathrm{U}$ was marginal significantly higher in the first block $\left(t_{(14)}=1.79, p=0.095\right)$, but not significantly different in the second or third block $\left(t_{(14)}=1.08, p=0.301 ; t_{(14)}=0.52\right.$, $p=0.610$, respectively).

In sum, these results clearly replicate the results by Raes and colleagues (2014) and Mertens and colleagues (2016). Most im- portantly, the $\mathrm{CS}^{+} \mathrm{P}$ elicited slightly but reliably higher fear ratings than the $\mathrm{CS}^{+} \mathrm{U}$, especially at the beginning of the test phase (Fig. 1; Raes et al., 2014; for similar findings in fear-potentiated startle responses, but not skin conductance responses, see Mertens et al., 2016). This indicates a dissociable contribution of prior actual CS-US pairings to the fear reaction to the $\mathrm{CS}^{+} \mathrm{P}$ in the testing phase.

\section{Similarity analyses: Experiment 1}

Different pattern similarity analyses are reported to allow for a comprehensive picture of the data. Importantly, each of those analyses were motivated by specific hypotheses, which are detailed below when discussing each analysis separately. We will first discuss an analysis that tested whether the responses to the different CSs were similar within the training and test phases. That is, did the ROIs respond more similarly to the $\mathrm{CS}^{+} \mathrm{P}$ and the $\mathrm{CS}^{+} \mathrm{U}$, than, for example, the $\mathrm{CS}^{+} \mathrm{P}$ and the $\mathrm{CS}^{-}$? Thereafter, we report an analysis that looked at the internal consistency of the separate patterns to each CS within a phase. Namely, did certain regions respond in a more consistent manner to one CS as opposed to another CS? Third, and most importantly, we tested whether the pattern response to $\mathrm{CS}^{+} \mathrm{P}$ during the training phase was a better predictor of itself during the test phase than it was to $\mathrm{CS}^{+} \mathrm{U}$ or $\mathrm{CS}^{-}$. As a post hoc analysis following up on this hypothesized result, we also tested whether regions that show this differential processing of the $\mathrm{CS}^{+} \mathrm{P}$ also show a relation with the difference in fear ratings. That is, we wanted to explore whether the difference in subjective fear experience as observed in the present study (Raes et al., 2014; replicating previous findings by Mertens et al., 2016) can be linked back to a neural trace of experience-based fear. Last, we will report a targeted patterninformed connectivity analyses by investigating parallels in trialto-trial pattern similarities between the ACC and the left and right amygdala, depending on CS type, as well as a broader connectivity analysis involving all six regions. Note that every analysis started with an omnibus ANOVA that included the factor region to detect between-region differences.

\section{Inter-CS similarities per phase}

We first confirmed that the selected ROIs process learned stimulus qualities (rather than merely processing the perceptual properties of the CSs). Specifically, we observed that the trial-averaged multivoxel activation patterns evoked by the $\mathrm{CS}^{+} \mathrm{P}$ and the $\mathrm{CS}^{+} \mathrm{U}$ were more similar to each other $\left(\mathrm{CS}^{+} \mathrm{PCS}^{+} \mathrm{U}\right.$ inter-CS similarity; Fig. 3, green bars) than each of them was to the trialaveraged patterns evoked by the $\mathrm{CS}^{-}$(comparison with $\mathrm{CS}^{-} \mathrm{CS}^{+} \mathrm{P}$ inter-CS similarity: $F_{(1,19)}=11.08, p=0.004$; Fig. 3, blue bars; with $\mathrm{CS}^{-} \mathrm{CS}^{+} \mathrm{U}$ inter-CS similarity: $F_{(1,19)}=18.59, p<0.001$; Fig. 3, red bars; for statistical procedures, see Materials and Methods). This was the case during both training and test (effects of phase: both $F$ 's $<1$ ), but, intriguingly, the effect differed significantly between regions (both $p^{\prime} s<0.004$ ). Specifically, in the left and right amygdalae, the $\mathrm{CS}^{+} \mathrm{P}$, which is the only CS whose acquired qualities result (in part) from experience, evoked activation patterns that were not more similar to $\mathrm{CS}^{+} \mathrm{U}$ patterns than to $\mathrm{CS}^{-}$patterns (both $F_{\mathrm{S}}<1$ ). This analysis suggests that while participants were instructed to treat the $\mathrm{CS}^{+} \mathrm{P}$ and $\mathrm{CS}^{+} \mathrm{U}$ similarly (and most fear-related regions also seem to reflect this), the amygdala could be sensitive to whether the fear value results from experience, and therefore did respond to them differently. This difference in responding was even comparable to the difference in responding to $\mathrm{CS}^{+} \mathrm{P}$ versus $\mathrm{CS}^{-}$. While we cannot prove that this effect is not a floor effect, we note that the other analyses below 

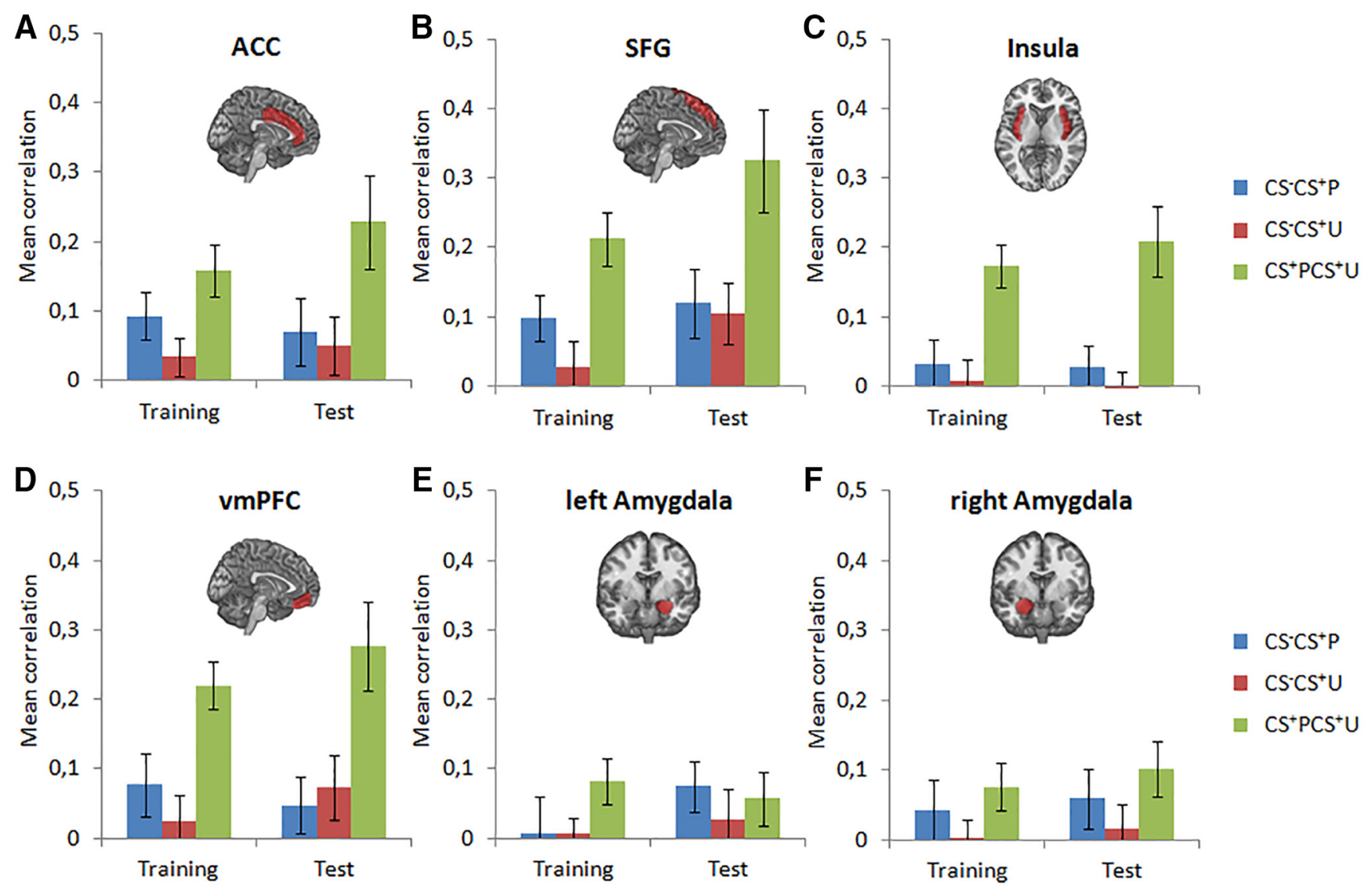

Figure 3. Inter-CS similarities per region and experimental phase (Experiment 1), based on the miniblock model (Fig. 2). $A-D$, More similar multivoxel activation patterns between the two $C S{ }^{+} S$ than between a $\mathrm{CS}^{+}$and the $\mathrm{CS}^{-}$indicate processing of learned stimulus value in the ACC $(\boldsymbol{A})$, superior frontal gyrus $(\boldsymbol{B} ; \mathrm{SFG})$, insula $(\boldsymbol{C})$, and ventromedial prefrontal cortex (D; vmPFC). $\boldsymbol{E}$, $\boldsymbol{F}$, The amygdala does not exhibit greater similarity between the instructed and experienced $\mathrm{CS}^{+}\left(\mathrm{CS}{ }^{+} \mathrm{P}\right)$ and the merely instructed $\mathrm{CS}^{+}\left(\mathrm{CS}^{+} \mathrm{U}\right)$ relative to the similarity between these $C S^{+}$S and the $\mathrm{CS}^{-}$. The error bars are \pm 1 SEM.

show reliable differences in the amygdala (sometimes even exclusively in the amygdala), speaking against the idea that activity in the amygdala regions was simply too variable or too noisy to detect reliable differences.

\section{Intra-CS similarities per phase}

Areas responsible for processing acquired as opposed to mere perceptual stimulus qualities are thought to exhibit more consistent activation patterns to each of the $\mathrm{CS}^{+} \mathrm{s}$ than to the $\mathrm{CS}^{-}$from one trial to the next of the experiment (Visser et al., 2011, 2013). However, note that one could also expect the opposite. Namely, regions responsive to dynamic trial-to-trial changes in a certain condition might show a lesser internal consistency. Therefore, these analyses only allow us to conclude that regions that show differences in these internal consistency measures between conditions must respond to these two conditions differently. Such a result would be another confirmation that such regions encode acquired stimulus qualities. For simplicity and robustness, we grouped trials into three miniblocks per phase and computed intra-CS similarities from one miniblock to the next. As expected, intra-CS ${ }^{+} \mathrm{P}$ similarity was significantly greater than intra-CS ${ }^{-}$ similarity (main effect of CS type: $F_{(1,19)}=18.11, p<0.001$; Fig. 4 ), and this difference decreased in the test phase relative to the training phase, which is consistent with the observed extinction in fear ratings in this phase $\left(F_{(1,19)}=4.49, p=0.047\right.$; no interactions with region, $F_{(5,95)}$ 's $<1.95$, $p$ 's $\left.>0.135\right)$. In stark contrast, the intra-CS ${ }^{+} \mathrm{U}$ versus intra-CS ${ }^{-}$similarity analysis (main effect of CS type: $\left.F_{(1,19)}=7.31, p=0.014\right)$ exhibited an interaction effect with region $\left(F_{(5,95)}=2.82, p=0.020\right.$; but no interactions with phase, $F$ s $<1$ ). The amygdalae were the only ROIs not showing significantly higher intra- $\mathrm{CS}^{+} \mathrm{U}$ than intra-CS ${ }^{-}$similarities (both $F_{(1,19)}$ 's $<1.25$, $p$ 's $>0.278$ ). That is, an analysis based on the temporal consistence of neural activation patterns (Visser et al., 2011, 2013) found no evidence that the amygdala processes the learned qualities of a merely instructed stimulus, the $\mathrm{CS}^{+} \mathrm{U}$.

Although all our analyses reflect between-region differences in different forms of fear processing between six identified fearrelated ROIs, one could also investigate whether completely unrelated ROIs show a fear response. Although it is hard to select completely unrelated regions, we investigated whether the superior temporal gyrus (i.e., auditory cortex) shows a similar main effect of fear conditioning (as suggested by an independent reader). Specifically, we zoomed in on the most reliable effect across all cortical fear-related regions: the enhanced correlation between patterns of responses to the instructed and experienced stimulus $\left(\mathrm{CS}^{+} \mathrm{P}\right)$ versus the neutral stimulus $\left(\mathrm{CS}^{-}\right)$. While this effect did reach significance in each of those regions, even after correcting for multiple comparisons, it did not reach significance in the superior temporal gyrus $\left(F_{(1,19)}=2.52, p=0.129\right)$.

Inter-CS similarities across phase

Both the $\mathrm{CS}^{+} \mathrm{P}$ and the $\mathrm{CS}^{+} \mathrm{U}$, but not the $\mathrm{CS}^{-}$, carry a representation of threat. Fear-related regions should therefore show $\mathrm{CS}^{+}$-evoked activation patterns that are more similar to each other than to $\mathrm{CS}^{-}$-evoked activation patterns. Intriguingly, the 

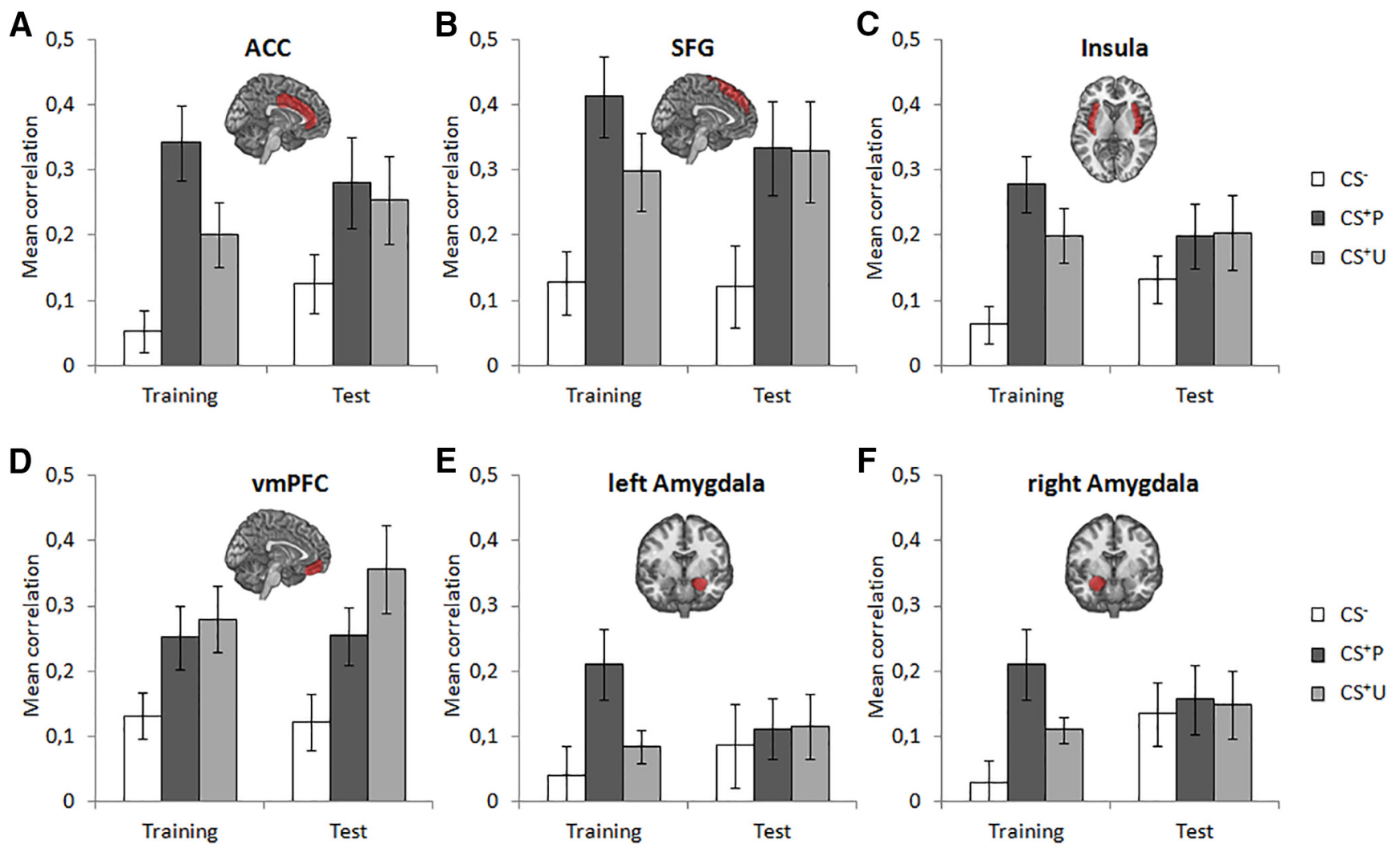

Figure 4. $\quad \boldsymbol{A}-\boldsymbol{F}$, Intra-CS similarities from miniblock to miniblock per CS type, region, and experimental phase (Experiment 1), based on the miniblock model (Fig. 2). Higher temporal consistency in intra- $\mathrm{CS}^{+}$than intra- $\mathrm{CS}^{-}$similarities indicates processing of learned stimulus qualities in a given ROl. This is not observed for the merely instructed $\mathrm{CS}^{+}\left(\mathrm{CS}^{+} \mathrm{U}\right)$ in the amygdalae $(\boldsymbol{E}, \boldsymbol{F})$. The error bars are \pm 1 SEM.

above set of similarity analyses indicated that the amygdala's neural activation pattern to the $\mathrm{CS}^{+} \mathrm{P}$ was not more similar to the $\mathrm{CS}^{+} \mathrm{U}$ than it was to $\mathrm{CS}^{-}$, whereas all other fear-related regions did show a greater similarity between their responses to $\mathrm{CS}^{+} \mathrm{P}$ and $\mathrm{CS}^{+} \mathrm{U}$ than between any of the two $\mathrm{CS}^{+} \mathrm{s}$ and the $\mathrm{CS}^{-}$(Fig. 3). Moreover, while all fear-related regions, including the amygdala, showed a higher consistency (within phase, but across miniblocks) in their neural pattern response to the $\mathrm{CS}^{+} \mathrm{P}$ than the $\mathrm{CS}^{-}$, only the nonamygdala fear-related regions also showed a higher consistency in their response to the $\mathrm{CS}^{+} \mathrm{U}$ than the $\mathrm{CS}^{-}$(Fig. 4). Together, these results are already suggestive of the idea that the amygdala is involved differently in the processing of an instructed and experienced versus a merely instructed fear contingency.

However, the central question in our analyses was whether brain regions involved in fear learning would respond differently to both $\mathrm{CS}^{+} \mathrm{s}$ in the test phase, despite the fact that the same verbal information was given about both $\mathrm{CS}^{+}$s. A neural trace of experience-based Pavlovian fear learning should be apparent from similarities between CS-evoked activation patterns during test and the activation pattern evoked by the $\mathrm{CS}^{+} \mathrm{P}$ during training $\left(\mathrm{CS}^{+} \mathrm{Ptr}\right)$, i.e., where the contingency was experienced and the Pavlovian fear memory was formed. Specifically, one should expect higher similarities between $\mathrm{CS}^{+}$Ptr patterns and the patterns evoked by the same $\mathrm{CS}$ during testing (i.e., $\mathrm{CS}^{+} \mathrm{Pte}$ ). If those similarities were larger than between $\mathrm{CS}^{+} \mathrm{Ptr}$ and $\mathrm{CSU}^{+}$te (as well as between $\mathrm{CS}^{+} \mathrm{Ptr}$ and $\mathrm{CS}^{-}$te), they would indicate a Pavlovian memory trace. By contrast, if $\mathrm{CS}^{+} \mathrm{PtrCS}^{+}$Pte similarities were no more pronounced than $\mathrm{CS}^{+} \mathrm{PtrCS}{ }^{+}$Ute similarities, this would indicate a more generalized representation of threat during testing that does not retain a specific experience-based mem- ory element. In this critical analysis, we observed a significantly higher similarity between $\mathrm{CS}^{+} \mathrm{Ptr}$ and $\mathrm{CS}^{+}$Pte $\left(\mathrm{CS}^{+} \mathrm{PtrCS}^{+} \mathrm{Pte}\right)$ as well as $\mathrm{CS}^{+} \mathrm{Ptr}$ and $\mathrm{CS}^{+} \mathrm{Ute}\left(\mathrm{CS}^{+} \mathrm{PtrCS}{ }^{+} \mathrm{Ute}\right)$, than between $\mathrm{CS}^{+} \mathrm{Ptr}$ and $\mathrm{CS}^{-}$te $\left(\mathrm{CS}^{+} \mathrm{PtrCS}^{+} \mathrm{Pte}\right.$ vs $\mathrm{CS}^{+} \mathrm{PtrCS}^{-}$te similarity: $F_{(1,19)}=19.36, p<0.001 ; \mathrm{CS}^{+} \mathrm{PtrCS}^{+} \mathrm{Ute} \mathrm{vs} \mathrm{CS}^{+} \mathrm{PtrCS}^{-}$te similarity: $F_{(1,19)}=14.27, p=0.001$; Figure 5). Importantly, $\mathrm{CS}^{+}$PtrCS ${ }^{+}$Pte did not differ from $\mathrm{CS}^{+} \mathrm{PtrCS}^{+}$Ute pattern similarity $\left(F_{(1,19)}=0.397, p=0.536\right)$. These results suggest both $\mathrm{CS}^{+} \mathrm{s}$ evoked similar threat-related processing during test. However, there was an interaction with region $\left(F_{(10,190)}=3.32, p=\right.$ 0.007; also when comparing the left and right amygdala only: $\left.F_{(2,18)}=3.31, p=0.047\right)$. Namely, the right amygdala exhibited $\mathrm{CS}^{+}$Pte patterns that were significantly more similar to $\mathrm{CS}^{+} \mathrm{Ptr}$ patterns than were both $\mathrm{CS}^{+}$Ute and $\mathrm{CS}^{-}$te patterns $\left(\mathrm{CS}^{+} \mathrm{PtrCS}^{+} \mathrm{Pte}\right.$ vs $\mathrm{CS}^{+}$PtrCS ${ }^{+}$Ute similarity: $t_{(19)}=2.204, p=0.040$; $\mathrm{CS}^{+} \mathrm{PtrCS}^{+}$Pte vs $\mathrm{CS}^{+} \mathrm{PtrCS}^{-}$te similarity: $t_{(19)}=3.990, p=$ 0.001 ; Fig. $5 F)$. The $\mathrm{CS}^{+}$Ute and $\mathrm{CS}^{-}$te patterns did not differ in their similarity to the $\mathrm{CS}^{+} \operatorname{Ptr}$ pattern $\left(t_{(19)}=1.013, p=0.324\right)$. Importantly, in all other regions, the patterns of $\mathrm{CS}^{+}$Pte and $\mathrm{CS}^{+}$Ute were not significantly different in their similarity to the pattern of $\mathrm{CS}^{+} \operatorname{Ptr}\left(\right.$ all $t_{(19)}$ 's $<1$. Hence, this analysis isolated a threat-related neural response during testing in the right amygdala that was exclusively evoked by the $\mathrm{CS}^{+} \mathrm{P}$, as opposed to the $\mathrm{CS}^{+} \mathrm{U}$, meeting our criterion for a Pavlovian trace of actually experienced CS-US pairings. Other regions appeared to register a merely instructed threat $\left(\mathrm{CS}^{+} \mathrm{U}\right)$ in the same way as a threat that is not only instructed but also previously experienced $\left(\mathrm{CS}^{+} \mathrm{P}\right)$.

The observation that activation in the right amygdala is more similar for $\mathrm{CS}^{+} \mathrm{Ptr}$ and $\mathrm{CS}^{+}$Pte than for $\mathrm{CS}^{+} \mathrm{Ptr}$ and $\mathrm{CS}^{+}$Ute might also reflect the fact that $\mathrm{CS}^{+} \mathrm{Ptr}$ and $\mathrm{CS}^{+}$Pte are visually 

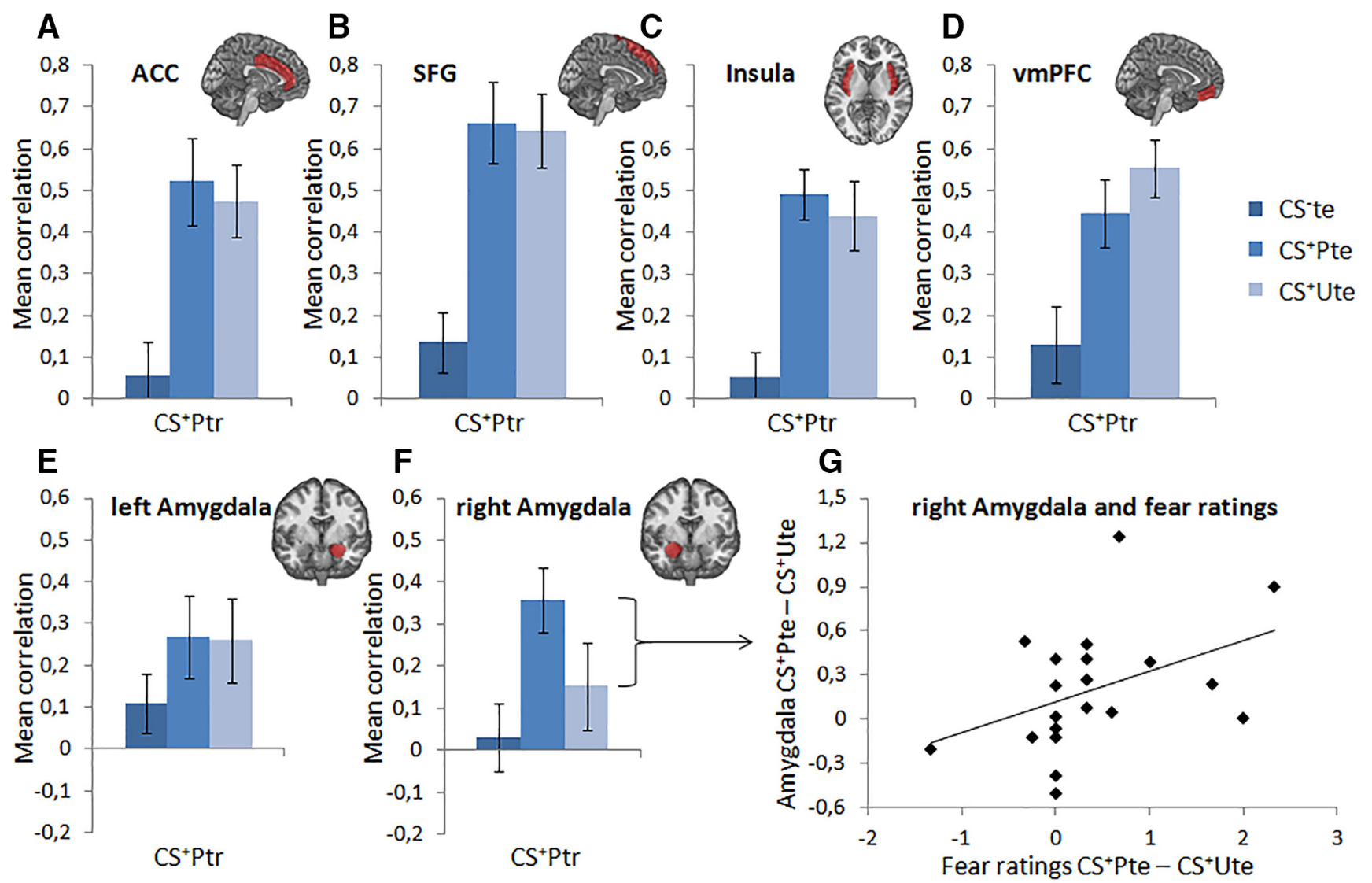

Figure 5. $A-\boldsymbol{F}$, Comparison of inter-CS similarities between each of the three different CS types from the test phase (CS ${ }^{-}$te, $C S^{+}$Pte, $C S^{+}$Ute) and the $C S^{+}$P pattern from the training phase $\left(C S^{+}\right.$Ptr), based on the phase model (Fig. 2), reveals $C S^{+}$P-specific processing of threat-related information in the right amygdala (Experiment 1): $C S^{+}$P-associated multivoxel activation patterns during test ( $\left(S^{+}\right.$Pte) are more similar to $C S^{+}$-associated patterns during training (CS ${ }^{+}$Ptr) than $C S^{+} U$-associated patterns during test (CS ${ }^{+}$Ute; $F$ ); other regions do not show such differentiation $(\boldsymbol{A}-\boldsymbol{E})$. The error bars are \pm 1 SEM. $\mathbf{G}$, Individual differences in the difference between $C S^{+}$PtrCS ${ }^{+}$Pte and $C S^{+}$PtrCS ${ }^{+}$Ute inter-CS similarities in the right amygdala were correlated with differences in fear ratings between $C S^{+} P$ and $C S^{+} U$ in the test phase.

more similar than $\mathrm{CS}^{+} \mathrm{Ptr}$ and $\mathrm{CS}^{+}$Ute. However, if this alternative explanation is correct, then activation for $\mathrm{CS}^{+} \mathrm{Utr}$ and $\mathrm{CS}^{+}$Ute should also be more similar than activation for $\mathrm{CS}^{+} \mathrm{Utr}$ and $\mathrm{CS}^{+}$Pte. No such difference was observed $\left(t_{(16)}=0.727, p=\right.$ 0.476). In fact, the similarity between $\mathrm{CS}^{+} \mathrm{Ptr}$ and $\mathrm{CS}^{+}$Pte was higher than that between the $\mathrm{CS}^{+} \mathrm{Utr}$ and $\mathrm{CS}^{+} \mathrm{Ute}\left(t_{(19)}=3.502\right.$, $p=0.002$ ).

Further supporting the encoding of this Pavlovian fear trace in the right amygdala, we observed a relation between $\mathrm{CS}^{+} \mathrm{P}$ specific right amygdala neural responses and the observed differential $\left(\mathrm{CS}^{+} \mathrm{P}>\mathrm{CS}^{+} \mathrm{U}\right)$ fear response, in that the difference between $\mathrm{CS}^{+} \mathrm{PtrCS}^{+}$Pte and $\mathrm{CS}^{+} \mathrm{PtrCS}^{+}$Ute pattern similarities as depicted in Figure $5 F$ predicted the difference in $\mathrm{CS}^{+}$Pte and $\mathrm{CS}^{+}$Ute fear ratings during test across participants (Spearman's $\rho=0.465, p=0.039$; Fig. $5 G$ ). This post hoc analysis should of course be treated with caution because our study (and its sample size) was not in the first instance set up to study intersubject correlations.

\section{Inter-region similarities in Intra-CS similarities}

If the right amygdala processes experience-based threat in a way that can be dissociated from its processing of instruction-based threat, it might also preferentially exchange that information with other threat areas. Specifically, we wondered, for comparison, whether $\mathrm{CS}^{+} \mathrm{P}$-related functional connectivity of the right amygdala with the ACC would differ from that of the left amygdala. The ACC is the region most prominently and consis- tently activated during fear-conditioning studies (Mechias et al., 2010; Fullana et al., 2015) and also exhibits strong structural and functional connectivity with the amygdalae (Etkin et al., 2006; Williams et al., 2006; Bissière et al., 2008; van Marle et al., 2010; for review, see Kim et al., 2011; Carlson et al., 2013). To this end, we opted to carry out voxel-pattern-informed connectivity analyses, which have recently been demonstrated to be more sensitive and reliable than standard connectivity analysis (Geerligs et al., 2016). To perform a similarity-based functional connectivity analysis, we used the trial-based model (Fig. 2A) and, separately for each subject, Spearman correlated the trial-by-trial intra-CS similarities per CS and phase (Fig. $6 \mathrm{~A}$ ) between regions, thereby indexing among these three regions similarities in how a CS pattern relates to itself across time (Fig. $6 B, C$; Kriegeskorte et al., 2008). We found that intra-CS ${ }^{+} \mathrm{P}$ relative to intra- $\mathrm{CS}^{+} \mathrm{U}$ similarity time courses from the right amygdala, but not the left amygdala, showed a higher correlation with corresponding ACC time courses (interaction between CS type and amygdala side: $F_{(1,19)}=5.68, p=0.028$; follow-up comparison of correlations between intra-CS ${ }^{+} \mathrm{P}$ and intra-CS ${ }^{+} \mathrm{U}$ similarity time courses from the right amygdala and ACC: $t_{(19)}=2.698, p=0.014$; from the left amygdala and ACC: $t_{(19)}=0.767, p=0.453$; Fig. $\left.6 B, C\right)$. These results further corroborate the conclusion that the right amygdala reacts differently to experienced and instructed fear, but also point toward an extended role of a larger network (Pessoa and Adolphs, 2010; Okon-Singer et al., 2015) by showing an 
A

CSte

123456789
CS+Pte

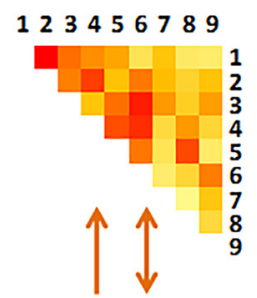

123456789
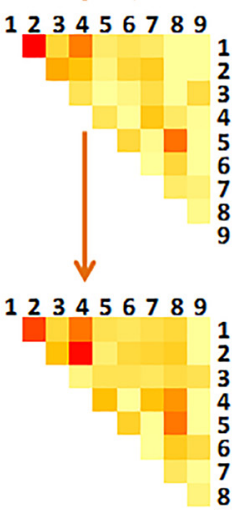

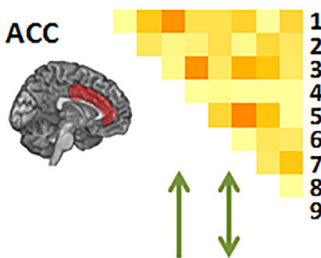

123456789
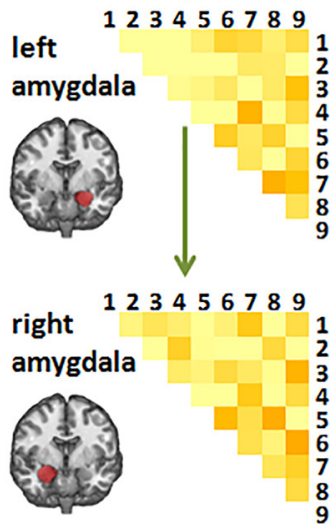

234

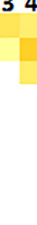

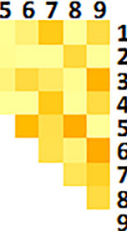

CS+Ute

123456789

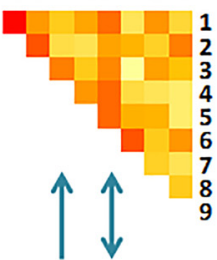

123456789

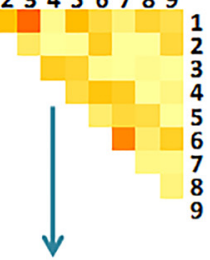

123456789

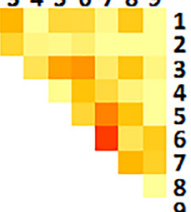

B

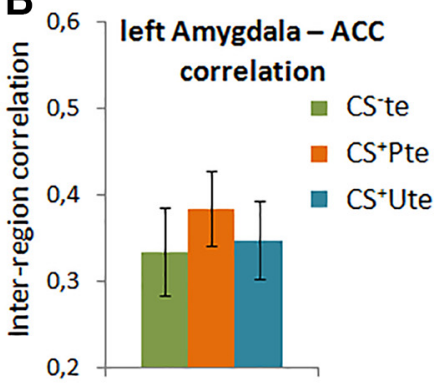

0.15

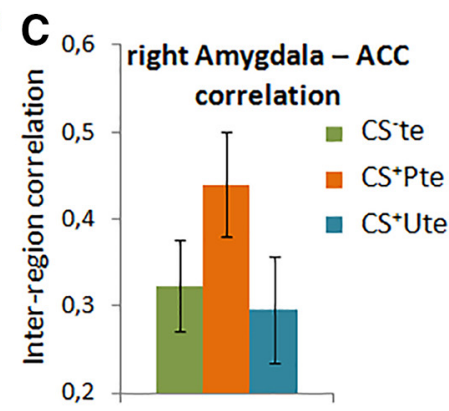

Figure 6. Inter-region similarity analyses between the ACC and left and right amygdalae (Experiment 1). $A$, Trial-by-trial intra-CS similarity matrices from the trial-based models for each region and CS type. On this basis, Spearman correlation coefficients were calculated between each combination of the resulting trial-by-trial ACC and left and right amygdala intra-CS similarity time courses, separately for each CS. B, C, The right amygdala showed a higher inter-region similarity with the ACC for the $C S^{+}$P specifically $(\boldsymbol{B})$, relative to the left amygdala, where no such effect was observed (C). The error bars are \pm 1 SEM.

increased functional connectivity with the ACC for communicating this experience-based component of fear learning.

To further illustrate this idea, and allow for a more comprehensive picture of the data, we also computed, for each CS-type separately, inter-region similarity matrices depicting each possible region-to-region connectivity (Fig. 7A). As a point of reference, we further included two occipital regions, namely the lateral occipital cortex and occipital pole. Multidimensional scaling analyses on Figure $7 C$ depict the relations between the six fearrelated regions for both $\mathrm{CS}^{+} \mathrm{s}$ in the test phase. We used twodimensional solutions (PROXSCAL, SPSS), as these offered the most optimal stress levels relative to the number of dimensions (i.e., the elbow in the scree plot). Most importantly, these analyses visualize how the connectivity patterns change depending on the CS-type processing. For example, Figure $7 C$ suggests a more integrated role for the right amygdala when it comes to processing the $\mathrm{CS}^{+} \mathrm{P}$. In fact, when comparing the overall connectivity between all six fear-related regions per CS (averaging all 15 possible connections; Fig. $7 B$ ), it appeared to be enhanced for $\mathrm{CS}^{+}$Pte relative to $\mathrm{CS}^{+} \mathrm{Ute}\left(t_{(19)}=2.633, p=0.016\right)$. When testing this for each region separately (its average connectivity with all other five regions for $\mathrm{CS}^{+}$Pte relative to $\mathrm{CS}^{+} \mathrm{Ute}$ ), the only two regions showing significantly stronger connectivity during $\mathrm{CS}^{+}$Pte processing were the right amygdala and the ACC $\left(t_{(19)}=2.780, p=0.012 ; t_{(19)}=2.541, p=0.020\right.$, respectively; all other regions, $t_{(19)}<1.91, p>0.071$ ), again suggesting that these two regions and their interaction play an important role in the learning or expressing of experience-based fear.

\section{Similarity analyses: Experiment 2}

In the second experiment, we used a different, but conceptually similar procedure to investigate whether we could replicate the observation that the right amygdala (compared with the left amygdala) dissociated between instructed and experienced (i.e., old) versus merely instructed (i.e., new) fear contingencies. Moreover, this experiment used stimuli belonging to different visual categories (houses vs faces) across different trials of the same condition, allowing us to study the similarity between pattern responses to the presentation of a house versus a face as a CS. The results, shown in Figure 8, hinted at a main effect of fear relevance $\left(\mathrm{CS}^{+}\right.$vs $\left.\mathrm{CS}^{-}, F_{(1,17)}=4.00, p=0.062\right)$, suggesting that object category independence (i.e., house-face pattern similarity) indexed activation of a threat representation. More importantly, there was a three-way interaction between CS type, CS novelty, and amygdala side $\left(F_{(1,17)}=5.38, p=0.033\right)$ that was qualified by a two-way interaction between CS type and novelty in the right amygdala $\left(F_{(1,17)}=5.36, p=0.033\right)$, but not the left amygdala $\left(F_{(1,17)}=0.133, p=0.720\right)$. More specifically, the right amygdala again differentiated between the processing of novel (i.e., merely instructed) and old (i.e., previously instructed and experienced) fear contingencies (Fig. $8 \mathrm{C}-\mathrm{H}$ ). Namely, the similarity between faces and houses was higher for $\mathrm{CS}^{+}$old than $\mathrm{CS}^{-}$old $\left(t_{(18)}=\right.$ $2.653, p=0.016)$, but not for $\mathrm{CS}^{+}$new than $\mathrm{CS}^{-}$new $\left(t_{(18)}=\right.$ $-0.217, p=0.831$ ). This result further supports our conclusion that the right amygdala carries a trace of the CS-US contingency experience made during Pavlovian fear conditioning. No other fear-related regions (Fig. 8) showed a similar CS type by novelty interaction (all $F$ 's $<1.782$, $p$ 's $>0.200$ ), again suggesting that the right amygdala was most sensitive in encoding a Pavlovian trace.

\section{Discussion}

Demonstrating a purely experience-based element in human Pavlovian fear conditioning and identifying its neural correlates has been a major goal of learning research over recent decades. While the strong phenomenological and functional homologies between human and nonhuman fear conditioning have always suggested language-independent processing in humans, previous efforts have not yielded conclusive evidence. Our new 
A
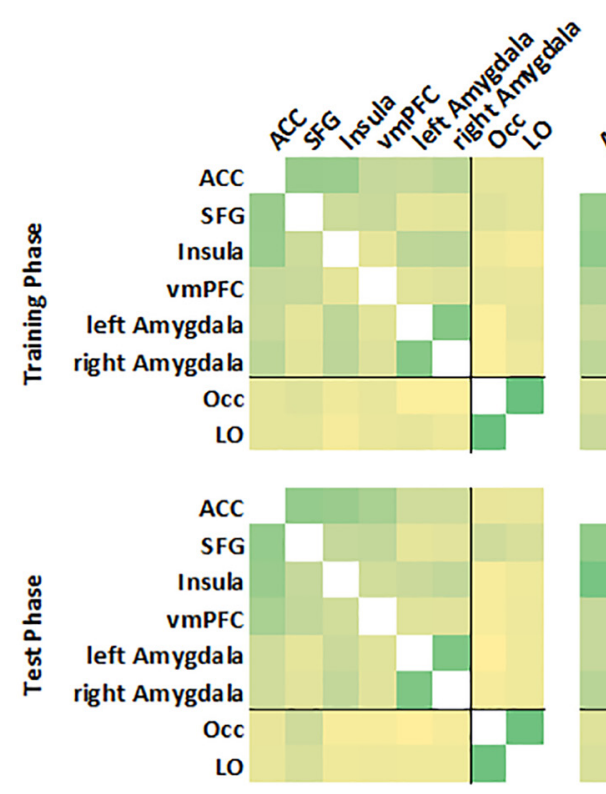

C
$\mathrm{CS}^{+} \mathrm{p}$
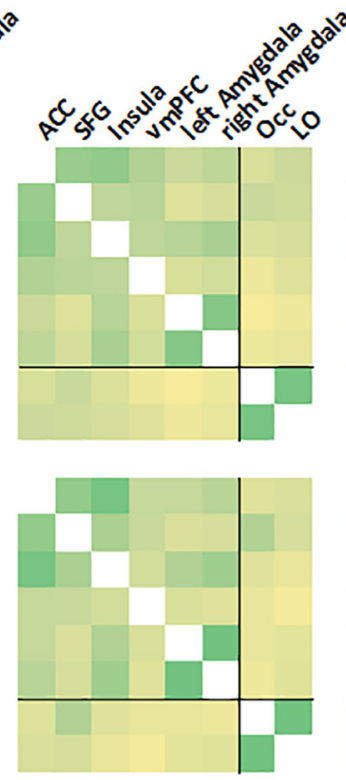

CS+P Test Phase
$\mathrm{CS}^{+} \mathrm{U}$

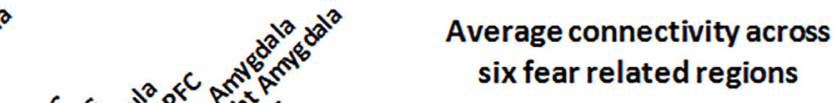

- vmPFC
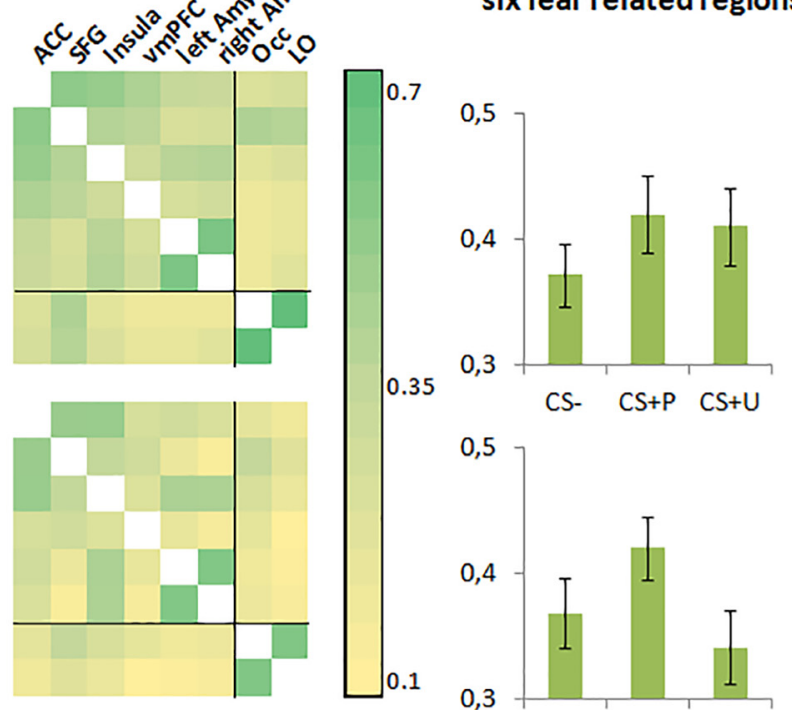

0,5

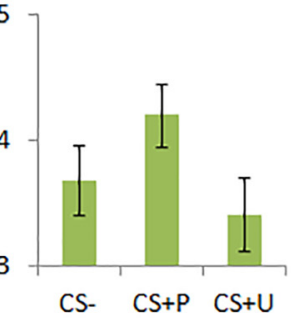

$\mathrm{CS}^{+} \mathrm{U}$ Test Phase

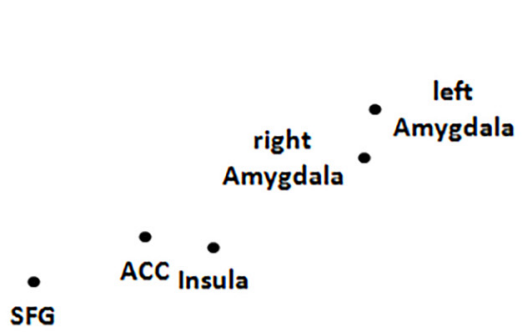

- vmPFC

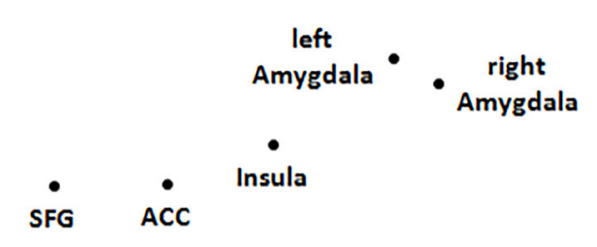

Figure 7. Inter-region similarity analyses per different CS type and experimental phase. $A$, Correlations were calculated between each combination of two regions' intra-CS similarity matrices from the trial-based models (Fig. 2), per CS and phase separately, as explained in Figure 6. B. The correlations across all fear-related regions were averaged and are presented per CS type and phase separately. C, Visual two-dimensional scaling depiction of the similarities between different regions for each $\mathrm{CS}^{+}$in the test phase separately.

approach is not dependent on controversial methods to exclude verbal or conscious processing (Mitchell et al., 2009) and exploits recent advances in the multivariate analysis of neural signatures of fear learning and memory (Li et al., 2008; Bach et al., 2011; Visser et al., 2011, 2013; Hauner et al., 2013; Dunsmoor et al., 2014). Because of these unique features, we are able to provide much sought evidence for experience-based threat processing. Specifically, using pattern similarity analyses, our two experiments demonstrated that the right amygdala was the only fear-related region whose neural activation pattern to experienced CSs was different from its neural pattern to merely instructed CSs. Of course, our data do not imply that the right amygdala does not process instructed threat information. Rather, it appears to respond in a unique way, perhaps in the form of specialized neural ensembles, to experiencebased threat information. More generally, the amygdala has also been implicated in other processes in addition to fear processing (Pessoa and Adolphs, 2010; Okon-Singer et al., 2015). Therefore, future studies should determine whether other separable experience-dependent neural traces in the right amygdala can be identified for other forms of learning as well.

The present findings seem to converge with those of previous fear-conditioning studies that were set up to single out uncon- scious fear conditioning. However, as noted above, the present study was not designed to study unconscious or implicit fear conditioning. Instead, the manipulations in the present study were made very explicit: participants were very much made aware of the instructions and the actual CS-US pairings. This way, our study tried to create conditions for instructed fear learning to override a hypothesized experience-based component to fear learning. Our results show that these instructions were successful in evoking a similar neural response to the merely instructed compared with the instructed and experienced stimulus in most fear-related regions, except in the right amygdala. It is possible that the present experience-based trace in the right amygdala is related to the one identified in previous unconscious fearconditioning studies. However, the present study cannot (and did not aim to) prove the hypothesized unconscious nature of this experience-based trace (Ohman and Mineka, 2001). Therefore, it does not distinguish between an experience-based memory trace that is generated fully automatically and unconsciously versus one that relies on conscious contingency knowledge.

The present observation of apparent hemispheric differences in threat processing in the amygdala also adds to another important and more specific question in fear research, that concerning 


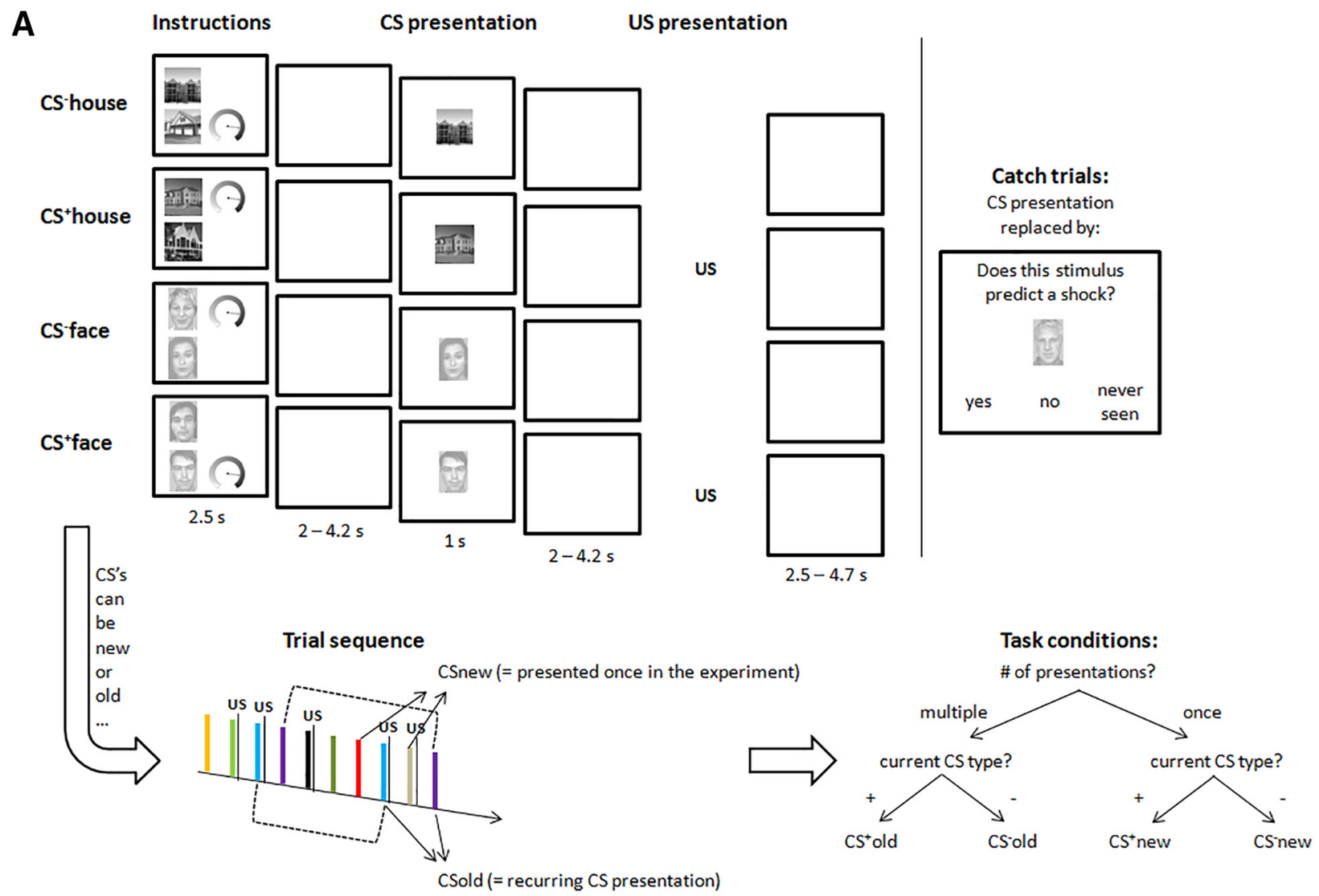

B

Face-House similarity:

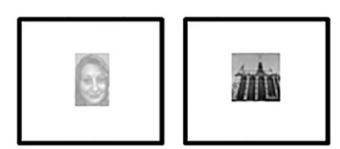

(CS presentation)
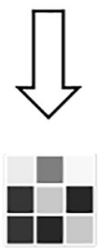

(voxel pattern response in region of interest)

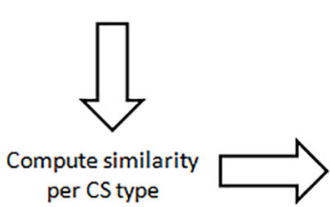

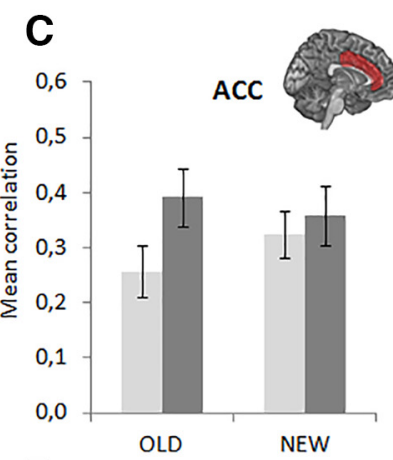

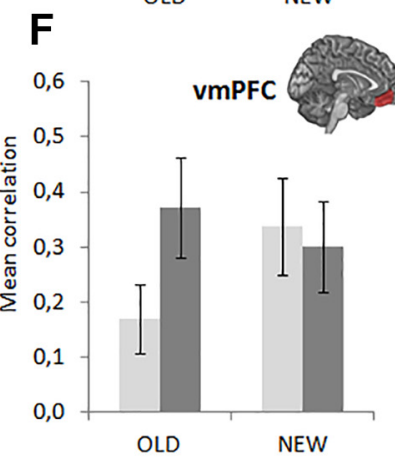

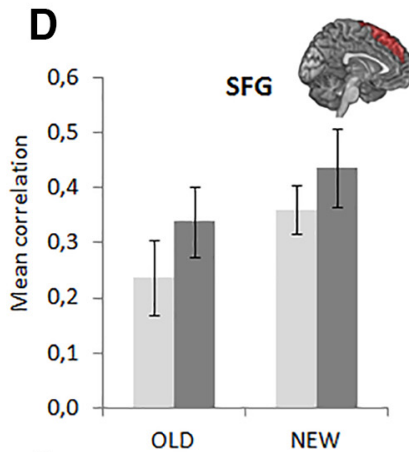

G

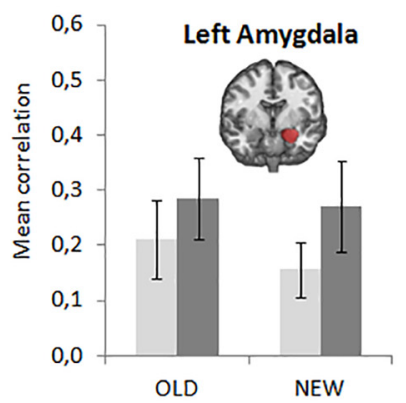

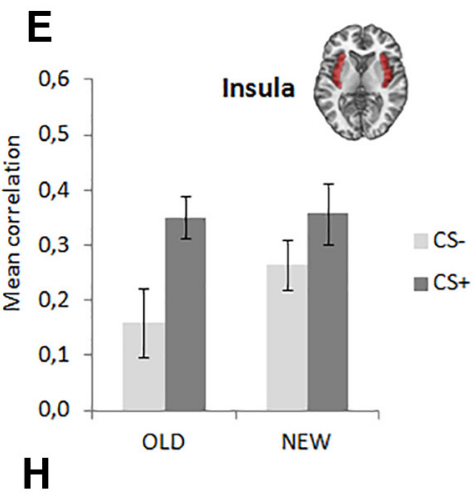

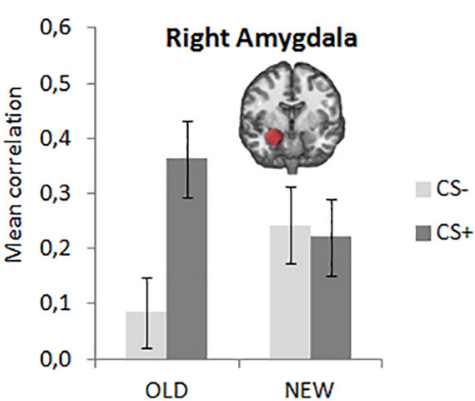

Figure 8. Procedure Experiment 2 and results. $\boldsymbol{A}$, Each trial consisted of a fear-contingency instruction and a $\left(S\right.$ presentation. The instruction indicated which of two pictures (CS ${ }^{+}$) would be followed by an electrical US by presenting an intensity meter next to that picture. $A$, lower left, Some CSs and instructions were recurring (old); others were always novel (new). Orthogonal to this, some instructions and subsequent $C S$ presentations used pictures of houses, others of faces. $C S^{+}$presentation was always followed by a US presentation. On a small subset of trials, $C S$ presentation was replaced by a catch question, to make certain that participants paid attention to the experiment. $\boldsymbol{B}$. The similarity analyses focused exclusively on pattern similarities between face and house pictures during CS presentations, for each CS type separately (CS ${ }^{+}$old, $\mathrm{CS}^{-}$old, $\mathrm{CS}^{+}$new, and $\mathrm{CS}{ }^{-}$new). $\mathbf{C}-\boldsymbol{H}$, These analyses revealed that the right, but not the left, amygdala showed a differential response to fear relevance as a function of novelty. Namely, the pattern response for houses and faces were more similar when these denoted a $\mathrm{CS}^{+}$than when they indicated a $\mathrm{CS}^{-}$. However, this difference was only present when the CSs had been instructed and experienced before (old CSs), but disappeared when they were novel. The error bars are \pm 1 SEM. 
the presence of amygdala lateralization (Baker and Kim, 2004; Sergerie et al., 2008). Our results clearly suggest that the right amygdala shows a separable neural response to actual CS-US pairings, whereas the left amygdala appears to be more susceptible to fear instructions. These findings agree with those from previous (lesion) studies suggesting that the right amygdala is associated with a fear response to experiencing negative events, while the left amygdala is more responsive to the verbally mediated cognitive representation of fear (Funayama et al., 2001; Phelps et al., 2001).

Last, our findings also fit well with those of another recent study by Atlas and colleagues (2016). In this study, Atlas and colleagues used two CSs that were both predictive of the US, but in different phases of the experiment. Crucially, they contrasted a condition in which this reversal in contingencies was always instructed to a condition where it was not, and observed that the amygdala was more responsive to the actual (changes in) contingencies rather than the instructions that preceded those. Interestingly, their analyses did not show a hemispheric difference, in contrast to earlier findings suggesting that the left amygdala can be responsive to instructions (present results; Funayama et al., 2001; Phelps et al., 2001). However, as also argued in their discussion, Atlas and colleagues (2016) focused on the effects of instruction in changing environments and examined dynamic learning-related responses, whereas our study used a manipulation where the contingencies did not change, and instructions were given full opportunity to override the hypothesized Pavlovian trace.

In sum, across two experiments, we investigated neural pattern responses in fear-related regions to experience-based fear processing in the face of verbal fear instructions. Our results show that verbal instructions were successful in evoking a similar neural response in fear-related regions to merely instructed versus instructed and experienced fear stimuli, except for the right amygdala. Instead, the human right amygdala showed a Pavlovian trace, suggesting it to be more sensitive to the actual experience of CS-US contingencies.

\section{References}

Atlas LY, Doll BB, Li J, Daw ND, Phelps EA (2016) Instructed knowledge shapes feedback-driven aversive learning in striatum and orbitofrontal cortex, but not the amygdala. Elife 5:e15192. CrossRef Medline

Bach DR, Weiskopf N, Dolan RJ (2011) A stable sparse fear memory trace in human amygdala. J Neurosci 31:9383-9389. CrossRef Medline

Baker KB, Kim JJ (2004) Amygdalar lateralization in fear conditioning: evidence for greater involvement of the right amygdala. Behav Neurosci 118:15-23. CrossRef Medline

Bissière S, Plachta N, Hoyer D, McAllister KH, Olpe HR, Grace AA, Cryan JF (2008) The rostral anterior cingulate cortex modulates the efficiency of amygdala-dependent fear learning. Biol Psychiatry 63:821-831. CrossRef Medline

Carlson JM, Cha J, Mujica-Parodi LR (2013) Functional and structural amygdala-anterior cingulate connectivity correlates with attentional bias to masked fearful faces. Cortex 49:2595-2600. CrossRef Medline

Critchley HD, Mathias CJ, Dolan RJ (2002) Fear conditioning in humans: the influence of awareness and autonomic arousal on functional neuroanatomy. Neuron 33:653-663. CrossRef Medline

Dolan RJ, Vuilleumier P (2003) Amygdala automaticity in emotional processing. Ann N Y Acad Sci 985:348-355. Medline

Dunsmoor JE, Kragel PA, Martin A, LaBar KS (2014) Aversive learning modulates cortical representations of object categories. Cereb Cortex 24: 2859-2872. CrossRef Medline

Etkin A, Egner T, Peraza DM, Kandel ER, Hirsch J (2006) Resolving emotional conflict: a role for the rostral anterior cingulate cortex in modulating activity in the amygdala. Neuron 51:871-882. CrossRef Medline

Fullana MA, Harrison BJ, Soriano-Mas C, Vervliet B, Cardoner N, ÀvilaParcet A and Radua J (2015) Neural signatures of human fear condition- ing: an updated and extended meta-analysis of fMRI studies. Mol Psychiatry 21:500-508.

Funayama ES, Grillon C, Davis M, Phelps EA (2001) A double dissociation in the affective modulation of startle in humans: effects of unilateral temporal lobectomy. J Cogn Neurosci 13:721-729. CrossRef Medline

Geerligs L, Cam-Can, Henson RN (2016) Functional connectivity and structural covariance between regions of interest can be measured more accurately using multivariate distance correlation. Neuroimage 135:1631. CrossRef Medline

Grillon C (2009) D-cycloserine facilitation of fear extinction and exposurebased therapy might rely on lower-level, automatic mechanisms. Biol Psychiatry 66:636-641. CrossRef Medline

Hauner KK, Howard JD, Zelano C, Gottfried JA (2013) Stimulus-specific enhancement of fear extinction during slow-wave sleep. Nat Neurosci 16:1553-1555. CrossRef Medline

Haxby JV, Gobbini MI, Furey ML, Ishai A, Schouten JL, Pietrini P (2001) Distributed and overlapping representations of faces and objects in ventral temporal cortex. Science 293:2425-2430. CrossRef Medline

Kim MJ, Loucks RA, Palmer AL, Brown AC, Solomon KM, Marchante AN, Whalen PJ (2011) The structural and functional connectivity of the amygdala: from normal emotion to pathological anxiety. Behav Brain Res 223:403-410. CrossRef Medline

Knight DC, Waters NS, Bandettini PA (2009) Neural substrates of explicit and implicit fear memory. Neuroimage 45:208-214. CrossRef Medline

Kriegeskorte N, Mur M, Bandettini P (2008) Representational similarity analysis-connecting the branches of systems neuroscience. Front Syst Neurosci 2:4. CrossRef Medline

LeDoux JE (2014) Coming to terms with fear. Proc Natl Acad Sci U S A 111:2871-2878. CrossRef Medline

Li W, Howard JD, Parrish TB, Gottfried JA (2008) Aversive learning enhances perceptual and cortical discrimination of indiscriminable odor cues. Science 319:1842-1845. CrossRef Medline

Maren S (2001) Neurobiology of Pavlovian fear conditioning. Annu Rev Neurosci 24, 897-931. CrossRef Medline

Mechias ML, Etkin A, Kalisch R (2010) A meta-analysis of instructed fear studies: implications for conscious appraisal of threat. Neuroimage 49: 1760-1768. CrossRef Medline

Mertens G, Kuhn M, Raes AK, Kalisch R, De Houwer J, Lonsdorf TB (2016) Fear expression and return of fear following threat instruction with or without direct contingency experience. Cogn Emot 30:968-984. CrossRef Medline

Mineka S, Ohman A (2002) Phobias and preparedness: the selective, automatic, and encapsulated nature of fear. Biol Psychiatry 52:927-937. CrossRef Medline

Mitchell CJ, De Houwer J, Lovibond PF (2009) The propositional nature of human associative learning. Behav Brain Sci 32:183-198; discussion 198 246. CrossRef Medline

Morris JS, Ohman A, Dolan RJ (1998) Conscious and unconscious emotional learning in the human amygdala. Nature 393:467-470. CrossRef Medline

Muhle-Karbe PS, Duncan J, De Baene W, Mitchell DJ, Brass M (2017) Neural coding for instruction-based task sets in human frontoparietal and visual cortex. Cerebral Cortex 27:1891-1905. CrossRef Medline

Norman KA, Polyn SM, Detre GJ, Haxby JV (2006) Beyond mind-reading: multi-voxel pattern analysis of fMRI data. Trends Cogn Sci 10:424-430. CrossRef Medline

Ohman A, Mineka S (2001) Fears, phobias, and preparedness: toward an evolved module of fear and fear learning. Psychol Rev 108:483-522. CrossRef Medline

Okon-Singer H, Hendler T, Pessoa L and Shackman AJ (2015) The neurobiology of emotion-cognition interactions: fundamental questions and strategies for future research. Front Hum Neurosci 9:58. CrossRef Medline

Olsson A, Phelps EA (2004) Learned fear of "unseen" faces after Pavlovian, observational, and instructed fear. Psychol Sci 15:822-828. CrossRef Medline

Olsson A, Phelps EA (2007) Social learning of fear. Nat Neurosci 10:10951102. CrossRef Medline

Pavlov IP (1927) Conditioned reflexes: an investigation of the physiological activity of the cerebral cortex. London: Oxford UP.

Pessoa L, Adolphs R (2010) Emotion processing and the amygdala: from a 'low road' to 'many roads' of evaluating biological significance. Nat Rev Neurosci 11:773-783. CrossRef Medline 
Phelps EA, O’Connor KJ, Gatenby JC, Gore JC, Grillon C, Davis M (2001) Activation of the left amygdala to a cognitive representation of fear. Nat Neurosci 4:437-441. CrossRef Medline

Raes AK, De Houwer J, De Schryver M, Brass M, Kalisch R (2014) Do CS-US pairings actually matter? A within-subject comparison of instructed fear conditioning with and without actual CS-US pairings. PLOS One 9:e84888. CrossRef Medline

Schultz DH, Helmstetter FJ (2010) Classical conditioning of autonomic fear responses is independent of contingency awareness. J Exp Psychol Anim Behav Process 36:495-500. CrossRef Medline

Sergerie K, Chochol C, Armony JL (2008) The role of the amygdala in emotional processing: a quantitative meta-analysis of functional neuroimaging studies. Neurosci Biobehav Rev 32:811-830. CrossRef Medline

Tabbert K, Merz CJ, Klucken T, Schweckendiek J, Vaitl D, Wolf OT, Stark R (2011) Influence of contingency awareness on neural, electrodermal and evaluative responses during fear conditioning. Soc Cogn Affect Neurosci 6:495-506. CrossRef Medline
Vadillo MA, Konstantinidis E, Shanks DR (2016) Underpowered samples, false negatives, and unconscious learning. Psychon Bull Rev 23:87-102. CrossRef Medline

van Marle HJ, Hermans EJ, Qin S, Fernández G (2010) Enhanced restingstate connectivity of amygdala in the immediate aftermath of acute psychological stress. Neuroimage 53:348-354. CrossRef Medline

Visser RM, Scholte HS, Kindt M (2011) Associative learning increases trial-by-trial similarity of BOLD-MRI patterns. J Neurosci 31:1202112028. CrossRef Medline

Visser RM, Scholte HS, Beemsterboer T, Kindt M (2013) Neural pattern similarity predicts long-term fear memory. Nat Neurosci 16:388-390. CrossRef Medline

Watson JB, Rayner R (1920) Conditioned emotional reactions. J Exp Psychol 3:1-14. CrossRef

Williams LM, Das P, Liddell BJ, Kemp AH, Rennie CJ, Gordon E (2006) Mode of functional connectivity in amygdala pathways dissociates level of awareness for signals of fear. J Neurosci 26:9264-9271. CrossRef Medline 